Article

\title{
NF-kappaB Regulates Redox Status in Breast Cancer Subtypes
}

\author{
Bruno R. B. Pires ${ }^{1,2, *(1)}$, Renata Binato ${ }^{1,2}$, Gerson M. Ferreira ${ }^{1,2}$, Rubens Cecchini ${ }^{3}$, \\ Carolina Panis ${ }^{1,4,+}$ and Eliana Abdelhay $1,2,+$ \\ 1 Laboratório de Célula-Tronco, Instituto Nacional de Câncer, Rio de Janeiro-RJ 20230-130, Brazil; \\ renata.binato@inca.gov.br (R.B.); gerson.ferreira@inca.gov.br (G.M.F.); carolinapanis@hotmail.com (C.P.); \\ eabdelhay@inca.gov.br (E.A.) \\ 2 Instituto Nacional de Ciência e Tecnologia para o Controle do Câncer, Rio de Janeiro-RJ 20231-050, Brazil \\ 3 Laboratório de Fisiopatologia e Radicais Livres, Universidade Estadual de Londrina, \\ Londrina-PR 86057-970, Brazil; cecchini@uel.br \\ 4 Laboratório de Mediadores Inflamatórios, Universidade Estadual do Oeste do Paraná, \\ Francisco Beltrão-PR 85605-010, Brazil \\ * Correspondence: brunoricardopires@gmail.com; Tel.: +55-21-3207-1874 \\ $\dagger$ These authors contributed equally to this work.
}

Received: 23 May 2018; Accepted: 22 June 2018; Published: 26 June 2018

\begin{abstract}
Oxidative stress (OS) is an indispensable condition to ensure genomic instability in cancer cells. In breast cancer (BC), redox alterations have been widely characterized, but since this process results from a chain of inflammatory events, the causal molecular triggers remain to be identified. In this context, we used a microarray approach to investigate the role of the main pro-oxidant transcription factor, nuclear factor-kappa $\mathrm{B}(\mathrm{NF}-\mathrm{kB})$, in gene profiles of $\mathrm{BC}$ subtypes. Our results showed that NF-KB knockdown in distinct BC subtypes led to differential expression of relevant factors involved in glutathione metabolism, prostaglandins, cytochrome $\mathrm{P} 450$ and cyclooxygenase, suggesting a relationship between the redox balance and NF- $\mathrm{KB}$ in such cells. In addition, we performed biochemical analyses to validate the microarray dataset focusing on OS and correlated these parameters with normal expression or NF-KB inhibition. Our data showed a distinct oxidative status pattern for each of the three studied BC subtype models, consistent with the intrinsic characteristics of each BC subtype. Thus, our findings suggest that NF- $\mathrm{KB}$ may represent an additional mechanism related to OS maintenance in $B C$, operating in various forms to mediate other important predominant signaling components of each BC subtype.
\end{abstract}

Keywords: breast cancer; subtypes; NFkappaB; redox; oxidative stress; microarray; gene expression

\section{Introduction}

Breast cancer $(\mathrm{BC})$ is a heterogeneous disease composed of multiple subtypes with distinct progressions, outcomes, and molecular features. This neoplasia is the leading cause of cancer-associated death among women worldwide. In the U.S., it is expected that approximately 270,000 new cases of female BC and more than 40,000 deaths will occur in 2018 [1]. Based on gene expression profiles, human BC may be classified in three major intrinsic groups: Luminal, HER2-enriched and triple-negative (TNBC) [2]. The Luminal subtype is characterized by the expression of estrogen and/or progesterone receptors (ER and PR, respectively); HER2-enriched overexpresses HER2/neu (human epidermal growth factor receptor 2); and TNBC shows negative expression for ER, PR and HER2 [2,3]. Recent advances have led to an understanding of the biological events in BC at the molecular level, but many issues must still be addressed. Molecular components from inflammatory networks have risen as major players in BC pathogenesis, especially nuclear factor (NF)-KB-driven signaling [4]. 
The NF- $\mathrm{kB}$ family consists of five conserved proteins, RelA (p65), RelB, c-Rel, p50, and p52. All of them share the conserved Rel homology domain (RHD) responsible for DNA binding, dimerization, and association with the repressor protein I $\kappa \mathrm{B}$. The NF- $\mathrm{kB}$ pathway comprises the canonical or noncanonical pathway. The classical pathway is activated by proinflammatory cytokine receptors, such as tumor necrosis factor (TNF)- $\alpha$, interleukin (IL)- $1 \beta$, the Toll-like receptor (TLR) family, T cell receptor (TCR), and $B$ cell receptor (BCR), ultimately leading to ubiquitin-dependent degradation of the repressor IKB through phosphorylation of the IKK complex (IKK $\alpha$, IKK $\beta$ and IKK $\gamma$ ). The repressor protein IкB degradation releases the p65/p50 dimer to translocate into the nucleus and activate the transcription of target genes [5,6]. Noncanonical signaling occurs downstream of cluster of differentiation 40 ligand (CD40L) and B cell-activating factor receptor (BAFF-R) pathways that lead to NF- $\mathrm{KB}$-inducing kinase (NIK) activation, resulting in phosphorylation of the homodimer IKK $\alpha$ and transfer of the phosphate group to the p100 subunit to be processed into p52. As a result, nuclear translocation of $\mathrm{p} 52 /$ RelB dimer occurs $[5,7]$.

Since cancer-related inflammation (CRI) was recognized as a hallmark of cancer, NF- $\mathrm{kB}$ assumed new importance in cancer studies [8,9]. NF- $\mathrm{kB}$ is a regulator of innate immunity and is responsible for inducing the expression of cyclooxygenase (COX)-2 and nitric oxide synthase (NOS), inflammatory cytokines such as IL-1, IL-6, IL-8, and TNF- $\alpha$, and chemokines such as CCL2 and CXCL8 $[4,5]$. Regarding $\mathrm{BC}$, constitutive activation of NF- $\mathrm{KB}$ contributes to several downstream pathways that regulate cellular proliferation, angiogenesis, evasion of apoptosis, induction of the cancer stem cell phenotype, oxidative stress (OS) and invasiveness [10-17]. Hence, the NF- $\mathrm{kB}$ pathway is a promising target for cancer therapy.

Despite wide knowledge about NF- $\mathrm{kB}$ in cancer, few studies have focused on understanding its role in the distinct molecular subtypes of $\mathrm{BC}$. Here, we sought to examine the role of NF- $\mathrm{KB}$ in $B C$ cells representing the main phenotypes of the disease (Luminal, HER2-enriched and TNBC). Therefore, we performed a series of microarray analyses after NF-kB silencing, aiming to unravel the main downstream pathways regulated by this transcription factor in each $\mathrm{BC}$ subtype. Our findings demonstrate that NF- $\mathrm{KB}$ has an important role in the redox balance in the studied BC subtype models, suggesting that NF- $\mathrm{KB}$ may represent an additional mechanism related to OS maintenance in $\mathrm{BC}$, operating in various forms to mediate other important predominant signaling components of each BC subtype.

\section{Materials and Methods}

\subsection{Cell Culture and Transfection}

The human breast cancer cell lines MDA-MB-231 (ATCC HTB-26, TNBC), HCC-1954 (ATCC CRL-2338, HER2) and MCF-7 (ATCC HTB-22, Luminal) were cultured in RPMI 1640 (Sigma-Aldrich, St. Louis, MO, USA) supplemented with 10\% fetal bovine serum (FBS), $2 \mathrm{mM}$ glutamine, 100 units $/ \mathrm{mL}$ penicillin, and $100 \mu \mathrm{g} / \mathrm{mL}$ streptomycin. The cells were cultured in a humidified $5 \% \mathrm{CO}_{2}$ atmosphere at $37^{\circ} \mathrm{C}$.

Specific short interference RNA (siRNA) (sc-29410, Santa Cruz Biotechnology, Dallas, TX, USA) was used to knock down the gene expression of NF- $\mathrm{kB} / \mathrm{p} 65$. An oligonucleotide that did not match any human coding cDNA was used as a negative control (Scramble, sc-37007, Santa Cruz). Transfections were performed using Lipofectamine LTX with Plus Reagent as per the manufacturer's instructions (Thermo Fisher, Waltham, MA, USA). As previously described [18], $4 \times 105$ cells were seeded in a 6-well plate and were then transfected with $50 \mathrm{nM}$ of siNF-kB or Scramble for $72 \mathrm{~h}$. The transfected cells were subsequently used for further experiments. 


\subsection{Chemicals}

Dehydroxymethylepoxyquinomicin (DHMEQ) was used to inhibit NF-kB/p65. As previously described [18], $10 \mu \mathrm{g} / \mathrm{mL}$ of DHMEQ was used in all experiments. All chemicals used in the oxidative stress analysis were purchased from Sigma-Aldrich.

\subsection{Expression Chip Array Data Analysis}

Total RNA from NF-kB-silenced and non-silenced cells was obtained using the RNeasy Mini kit (Qiagen, Hilden, Germany) following the manufacturer's instructions. Next, $100 \mathrm{ng}$ of each RNA was used to synthesize and biotinylate cRNA according to the GeneChip whole transcription (WT) sense target-labeling assay (Thermo Fisher). The biotinylated cRNA was hybridized to the GeneChip human gene 1.0 ST array (Thermo Fisher), washed and stained according to the manufacturer's protocols. The GeneChip arrays were scanned using GeneChip ${ }^{\circledR}$ Scanner 3000. Affymetrix Expression Console ${ }^{\mathrm{TM}}$ software v.1.0 (Thermo Fisher) was used to create summarized expression values (CHP-files). Data were analyzed using the Affymetrix Transcriptome Analysis Console (Thermo Fisher), whereby differentially expressed genes with $\geq 1$.5-fold-change were used as criteria to define up-regulation or down-regulation compared with the corresponding Scramble.

In silico analysis of gene ontology, biological processes and signaling pathways, that were altered as a consequence of NF- $\mathrm{kB}$ knockdown, was performed using KEGG [19] and PANTHER software [20]. A pathway enrichment analysis was performed using MetaCore software v.6.35 (Thomson Reuters, Toronto, Canada) A Venn diagram was generated using the online software of Bioinformatics \& Evolutionary Genomics [21].

\subsection{Real-Time Reverse Transcription Polymerase Chain Reaction (RT-qPCR)}

Two micrograms of RNA were subjected to the DNAse Amplification Grade I Kit (Thermo Fisher) for removal of DNA contamination and reverse-transcribed into cDNA using the Superscript-III kit (Thermo Fisher) per the manufacturer's protocol. Real-Time reverse transcription PCR (RT-qPCR) was performed with SYBR Green Master Mix (Thermo Fisher) in a Rotor-Gene Q (Qiagen), and the conditions were as follows: $95^{\circ} \mathrm{C}$ for $10 \mathrm{~min}$, followed by 45 cycles of $30 \mathrm{~s}$ at $95^{\circ} \mathrm{C}, 30 \mathrm{~s}$ at $60^{\circ} \mathrm{C}$ and $30 \mathrm{~s}$ at $72{ }^{\circ} \mathrm{C}$. The primers used are described in Table 1 . The mean of the housekeeping genes ACTB and GAPDH was used as the reference expression for the mRNA levels. Each sample was examined in triplicate. The fold expression was calculated according to the $\Delta \Delta \mathrm{Ct}$ method [22].

Table 1. Primer sequences of the investigated genes.

\begin{tabular}{cc}
\hline Primer & Sequence \\
\hline ACTB forward & $5^{\prime}$-TTCCTTCCTGGGCATGGAGTC-3' \\
ACTB reverse & $5^{\prime}$-AGACAGCACTGTGTTGGCGTA-3' \\
GAPDH forward & $5^{\prime}$-ATTCCACCCATGGCAAATTC-3 \\
GAPDH reverse & $5^{\prime}$-GGCGTGGATGGGTCTTTCA-3' \\
BRCA1 forward & $5^{\prime}$-GACAGAGGACAATGGCTTCC-3' \\
BRCA1 reverse & $5^{\prime}$-AGCTCCTGGCACTGGTAGAG-3' \\
BRCA2 forward & $5^{\prime}$-GCCGTACACTGCTCAAATCA-3' \\
BRCA2 reverse & $5^{\prime}$-TTTGAAGTCATCTGGGCTGA-3' \\
TP63 forward & $5^{\prime}$-GAGGTTGGGCTGTTCATCAT-3' \\
TP63 reverse & $5^{\prime}$-GAGGAGAATTCGTGGAGCTG-3' \\
PEX1 forward & $5^{\prime}$-TGACTGCACTTGGTCACACA-3' \\
PEX1 reverse & $5^{\prime}$-CTGTCCAGGTCGAAACATTG-3' \\
HPGD forward & $5^{\prime}$-CCATTTGTCCAGGCTTTGTT-3' \\
HPGD reverse & $5^{\prime}$-AATCAATGGTGGGTCCAAAA-3' \\
ARG2 forward & $5^{\prime}$-GGCTGAGGTGGTTAGCAGAG-3' \\
ARG2 reverse & $5^{\prime}$-ACAAAGGTCTGGGCAGTGTC-3' \\
GPX2 forward & $5^{\prime}$-TTGCAACCAATTTGGACATC-3' \\
\hline
\end{tabular}


Table 1. Cont.

\begin{tabular}{cc}
\hline Primer & Sequence \\
\hline GPX2 reverse & $5^{\prime}$-TTTTTGGACAAGGGTGAAGG-3' \\
COX8C forward & $5^{\prime}$-GGAAATGGCTGTTGGACTTG-3' \\
COX8C reverse & $5^{\prime}$-ACTGCTTCAGGTTGCCTAGC-3 \\
OXR1 forward & $5^{\prime}$-TTGGTGCGTTAGCATCTGAG-3' \\
OXR1 reverse & $5^{\prime}$-CAAATTCTCCTCCTCCACCA-3 \\
TMX1 forward & $5^{\prime}$-GCAGATTGCCTTTGTCCTTC-3' \\
TMX1 reverse & $5^{\prime}$-TTCTTCATCCGCCTCTTGTT-3' \\
\hline
\end{tabular}

\subsection{Biochemical Analysis}

Based on the microarray results, we chose to investigate oxidative-stress related genes for the validation step. The oxidative status of the total content of cells and supernatant $(5 \times 105 \mathrm{cells} / \mathrm{mL})$ was determined by the quantification of total thiol content and estimation of nitric oxide levels by nitrite (NO) and lipid peroxidation profiling. The thiol content was measured by the addition of $320 \mu \mathrm{L}$ of Tris-EDTA buffer $(0.25 \mathrm{M} / 0.02 \mathrm{M}, \mathrm{pH}$ 8.2) and $40 \mu \mathrm{L}$ of DTNB (5,5'-dithiobis(2-nitrobenzoic acid) $-0.01 \mathrm{M}$ ) to $50 \mu \mathrm{L}$ of sample containing cells and supernatant. The resulting yellow compound was measured at $412 \mathrm{~nm}$, and the results are represented as $\mu \mathrm{M}$ of thiol [23]. For NO levels, aliquots of $60 \mu \mathrm{L}$ of sample containing cells and supernatant were deproteinized in $50 \mu \mathrm{L}$ of $\mathrm{ZnSO}_{4}(75 \mathrm{mM})$, centrifuged at 10,000 rpm for $2 \mathrm{~min}$ and then mixed with $70 \mu \mathrm{L}$ of $\mathrm{NaOH}(55 \mathrm{mM})$. After centrifugation at $10,000 \mathrm{rpm}$ for $5 \mathrm{~min}, 150 \mu \mathrm{L}$ of supernatant was added to $50 \mu \mathrm{L}$ of glycine buffer $(45 \mathrm{~g} / \mathrm{L}, \mathrm{pH} 9.7)$ and incubated for 10 min with cadmium granules (Fluka, Sigma-Aldrich, St. Louis, MO, USA) previously activated by $\mathrm{CuSO}_{4}(5 \mathrm{mM}, 5 \mathrm{~min})$ to convert nitrate to nitrite. Next, of $50-\mu \mathrm{L}$ aliquots were mixed with Griess reagent for $10 \mathrm{~min}$, and the absorbance was measured at $550 \mathrm{~nm}$ [24]. The results are expressed as $\mu \mathrm{M}$ of nitrite. Lipid peroxidation profiling was determined using $500 \mu \mathrm{L}$ of sample containing cells and supernatant, supplemented with $500 \mu \mathrm{L}$ of phosphate buffer $\left(\mathrm{K}_{2} \mathrm{HPO}_{4} 30 \mathrm{mM}\right.$ in $\mathrm{KCl} 1.15 \%$, pH 7.4, $37^{\circ} \mathrm{C}$ ) and $20 \mu \mathrm{L}$ of tert-butyl hydroperoxide (3 mM) [25]. Data were quantified using a Glomax luminometer (Promega, Madison, WI, USA), and the results were analyzed with OriginLab 7.5 (OriginLab) software and expressed as relative light units (RLUs) in $20 \mathrm{~min}$.

\subsection{Statistical Analysis}

All data are expressed as the mean \pm standard deviation (SD) of at least three independent experiments and were analyzed by a two-tailed Student's $t$-test or ANOVA with GraphPad Prism v.5 (GraphPad Inc., San Diego, CA, USA). p-values < 0.05 were considered statistically significant.

\section{Results}

\subsection{NF-אB/p65 Inhibition Altered the Gene Expression Profile of Redox Signaling}

We have recently described the importance of $\mathrm{NF}-\mathrm{kB} / \mathrm{p} 65$ in the regulation of epithelial-to-mesenchymal transition (EMT) in breast cancer cells [18]. For that purpose, we silenced NF- $\mathrm{B}$ / p65 using the siRNA-strategy and confirmed the knockdown at both transcript and protein levels, as previously reported [18]. Here, we questioned its role in other biological processes, focusing on understanding distinct molecular breast cancer subtypes.

Initially, we evaluated the endogenous expression of NF- $\mathrm{B} / \mathrm{p} 65$ in our models, which was detectable in all studied cell lines (Figure S2). Then, we conducted the same NF- $\mathrm{kB}$-silencing protocol described in our previous article [18].

To determine the global gene expression profile in NF- $\mathrm{kB}$-silenced human breast cancer cells, we performed a comparative transcriptome analysis by expression chip array assay. Using this approach, transcript levels of NF-kB knockdown in MDA-MB-231, HCC-1954 and MCF-7 cells were used and compared with their scramble counterparts from each cell line. As a consequence of NF- $\kappa \mathrm{B} /$ p65 knockdown, considering a $\geq 1.5$-fold change as the cut-off to define up- or down-regulation, 
2017 genes were differentially expressed in NF- $\mathrm{B}$ / p65-silenced (siNF- $\mathrm{kB}$ ) MDA-MB-231, 564 genes in

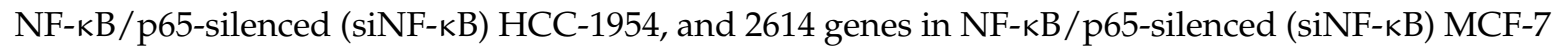
cells. The total numbers of increased and decreased genes are shown in Figure 1. Notably, more down-regulated genes were found in MCF-7 cells, while the most up-regulated genes were found in MDA-MB-231 cells.

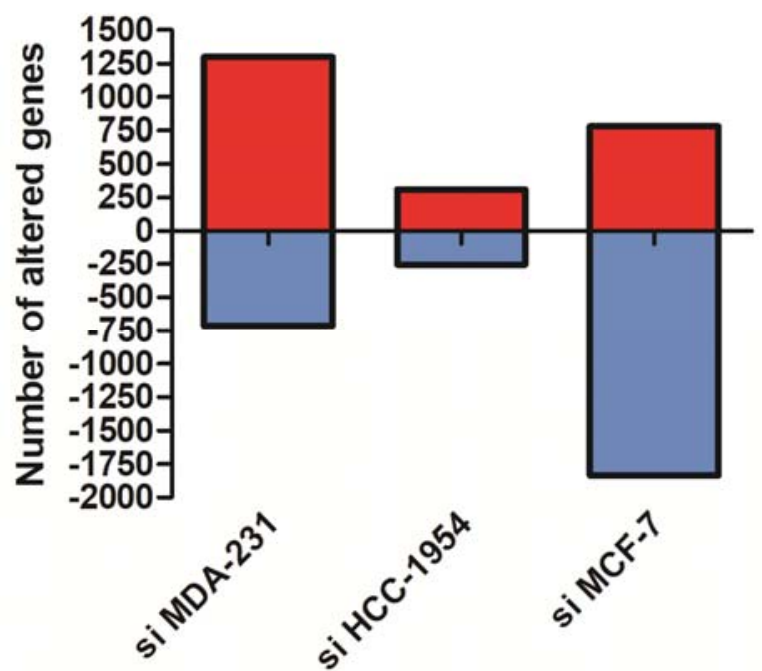

\section{$\square$ Up-regulated $\square$ Down-regulated}

Figure 1. Differentially expressed genes identified by the chip array assay showing increased and decreased genes in breast cancer cells with silenced nuclear factor-kappa B (NF-kB)/p65 compared with their scramble counterparts. Positive values (red columns) correspond to the number of up-regulated genes, and negative values (blue columns) correspond to the number of down-regulated genes.

As each studied cell line corresponded to one specific BC subtype, different genes were altered in response to NF- $\mathrm{KB}$ silencing. Through a pathway enrichment analysis using MetaCore software v.6.35 (Thomson Reuters, Toronto, Canada), we found Oxidative stress cellular signaling among the Top 20 pathways most representative in all differentially expressed gene lists: siNFkB MDA-MB-231 $\left(p\right.$-value $\left.=1.180 \times 10^{-7}\right)$, siNFkB HCC-1954 $\left(p\right.$-value $\left.=4.294 \times 10^{-3}\right)$, and siNFkB MCF-7 $\left(p\right.$-value $\left.=4.557 \times 10^{-4}\right)$. We also identified pivotal members of the redox balance using the PANTHER and KEGG gene ontology tools, as described in Table 2. Thus, the focus of the validation dataset was on OS experiments to understand biological significance of OS for the intrinsic BC phenotypes during NF-kB silencing. 
Table 2. List of oxidative stress-related genes with altered expression in NF- $\mathrm{kB}-$ silenced breast cancer cell lines.

\begin{tabular}{|c|c|c|c|c|}
\hline \multicolumn{5}{|c|}{ siNFKB MDA-MB-231 } \\
\hline Fold Change & Gene Symbol & Description & GO Biological Process & GO Molecular Function \\
\hline 25.9 & ALDH1A3 & aldehyde dehydrogenase 1 family, member A3 & retinoic acid biosynthetic process, metabolic process & $\begin{array}{l}\text { aldehyde dehydrogenase (NAD) activity; oxidoreductase } \\
\text { activity }\end{array}$ \\
\hline 21.19 & AKR1B10 & $\begin{array}{l}\text { aldo-keto reductase family 1, member B10 (aldose } \\
\text { reductase) }\end{array}$ & $\begin{array}{l}\text { retinoid metabolic process; cellular aldehyde metabolic } \\
\text { process; steroid metabolic process; oxidation-reduction } \\
\text { process }\end{array}$ & aldo-keto reductase (NADP) activity; oxidoreductase activity \\
\hline 11.78 & TP63 & tumor protein $\mathrm{p} 63$ & replicative cell aging & DNA binding transcription factor activity \\
\hline 10.72 & DHRS9 & dehydrogenase/reductase (SDR family) member 9 & $\begin{array}{l}\text { androgen metabolic process; progesterone metabolic } \\
\text { process; retinol metabolic process }\end{array}$ & $\begin{array}{l}\text { alcohol dehydrogenase (NAD) activity; oxidoreductase } \\
\text { activity; oxidoreductase activity }\end{array}$ \\
\hline 9.4 & PTGES & prostaglandin $\mathrm{E}$ synthase & $\begin{array}{l}\text { prostaglandin metabolic process; cyclooxygenase pathway; } \\
\text { response to lipopolysaccharide; fatty acid metabolic process }\end{array}$ & glutathione binding; isomerase activity \\
\hline 8.23 & DHRS3 & dehydrogenase/reductase (SDR family) member 3 & $\begin{array}{l}\text { retinol metabolic process; oxidation-reduction process; } \\
\text { metabolic process }\end{array}$ & $\begin{array}{l}\text { nucleotide binding; dehydrogenase activity; electron carrier } \\
\text { activity; oxidoreductase activity }\end{array}$ \\
\hline 7.02 & RDH10 & retinol dehydrogenase 10 (all-trans) & retinoid metabolic process & oxidoreductase activity \\
\hline 5.01 & GPX2 & glutathione peroxidase 2 (gastrointestinal) & $\begin{array}{l}\text { oxidation-reduction process; response to oxidative stress; } \\
\text { cellular oxidant detoxification }\end{array}$ & $\begin{array}{l}\text { electron carrier activity; peroxidase activity; oxidoreductase } \\
\text { activity }\end{array}$ \\
\hline 5.01 & PTGS2 & prostaglandin-endoperoxide synthase 2 (pro & staglandin $\mathrm{G} / \mathrm{H}$ synthase and cyclooxygenase) & $\begin{array}{l}\text { peroxidase activity; lipid binding; enzyme binding; heme } \\
\text { binding; metal ion binding; oxidoreductase activity }\end{array}$ \\
\hline 4.57 & PTGFRN & prostaglandin F2 receptor inhibitor & lipid particle organization & protein binding \\
\hline 3.5 & AKR1C2 & $\begin{array}{l}\text { aldo-keto reductase family 1, member C2; aldo-keto } \\
\text { reductase family } 1 \text { member C2-like }\end{array}$ & $\begin{array}{l}\text { lipid metabolic process; prostaglandin metabolic process; } \\
\text { steroid metabolic process }\end{array}$ & oxidoreductase activity; carboxylic acid binding \\
\hline 3.48 & STS & steroid sulfatase (microsomal), isozyme S & steroid metabolic process & $\begin{array}{l}\text { steryl-sulfatase activity; sulfuric ester hydrolase activity; } \\
\text { metal ion binding; catalytic activity; hydrolase activity }\end{array}$ \\
\hline 3.42 & GSTT1 & glutathione S-transferase theta 1 & $\begin{array}{l}\text { glutathione metabolic process; xenobiotic metabolic process; } \\
\text { oxidation-reduction process }\end{array}$ & $\begin{array}{l}\text { glutathione transferase activity; glutathione peroxidase } \\
\text { activity; protein binding }\end{array}$ \\
\hline 3.13 & $M A O A$ & monoamine oxidase A & xenobiotic metabolic process; oxidation-reduction process & primary amine oxidase activity; oxidoreductase activity \\
\hline 3.05 & CYP4B1 & cytochrome P450, family 4, subfamily B, polypeptide 1 & $\begin{array}{l}\text { cellular aromatic compound metabolic process; exogenous } \\
\text { drug catabolic process; oxidation-reduction process }\end{array}$ & iron ion binding; oxidoreductase activity \\
\hline 2.92 & РІКЗС2B & $\begin{array}{l}\text { phosphatidylinositol-4-phosphate 3-kinase, catalytic } \\
\text { subunit type } 2 \text { beta }\end{array}$ & $\begin{array}{l}\text { phospholipid metabolic process; protein phosphorylation; } \\
\text { inflammatory response }\end{array}$ & lipid kinase activity; ATP binding \\
\hline 278 & $C P$ & ceruloplasmin (ferroxidase) & copper ion transport; oxidation-reduction process; & $\begin{array}{l}\text { ferroxidase activity; copper ion binding; chaperone binding; } \\
\text { oxidoreductase activity; metal ion binding }\end{array}$ \\
\hline 2.62 & $S Q R D L$ & sulfide quinone reductase-like (yeast) & $\begin{array}{l}\text { sulfur amino acid metabolic process; cellular nitrogen } \\
\text { compound metabolic process; oxidation-reduction process }\end{array}$ & $\begin{array}{l}\text { sulfide:quinone oxidoreductase activity; oxidoreductase } \\
\text { activity }\end{array}$ \\
\hline 2.52 & CYB5A & cytochrome b5 type A (microsomal) & $\begin{array}{l}\text { L-ascorbic acid metabolic process; response to cadmium ion; } \\
\text { oxidation-reduction process }\end{array}$ & $\begin{array}{l}\text { aldo-keto reductase (NADP) activity; enzyme binding; heme } \\
\text { binding; metal ion binding }\end{array}$ \\
\hline 2.39 & SEPW1 & selenoprotein $\mathrm{W}, 1$ & cell redox homeostasis & antioxidant activity; selenium binding \\
\hline 2.38 & IDO1 & indoleamine 2,3-dioxygenase 1 & immune system process; chronic inflammatory response & $\begin{array}{l}\text { electron carrier activity; heme binding; metal ion binding; } \\
\text { oxidoreductase activity }\end{array}$ \\
\hline 2.36 & NDUFB9 & $\begin{array}{l}\text { NADH dehydrogenase (ubiquinone) } 1 \text { beta subcomplex, } \\
9,22 \mathrm{kDa}\end{array}$ & $\begin{array}{l}\text { mitochondrial electron transport, NADH to ubiquinone; } \\
\text { respiratory electron transport chain; oxidation-reduction } \\
\text { process }\end{array}$ & protein binding; NADH dehydrogenase activity \\
\hline
\end{tabular}


Table 2. Cont.

\begin{tabular}{|c|c|c|c|c|}
\hline \multicolumn{5}{|c|}{ siNFKB MDA-MB-231 } \\
\hline Fold Change & Gene Symbol & Description & GO Biological Process & GO Molecular Function \\
\hline 2.35 & SRD5A3 & steroid 5 alpha-reductase 3 & $\begin{array}{l}\text { androgen biosynthetic process; oxidation-reduction process; } \\
\text { protein glycosylation; lipid metabolic process }\end{array}$ & oxidoreductase activity \\
\hline 2.21 & $B L V R B$ & biliverdin reductase $B$ (flavin reductase (NADPH)) & heme catabolic process; oxidation-reduction process & $\begin{array}{l}\text { riboflavin reductase (NADPH) activity; oxidoreductase } \\
\text { activity }\end{array}$ \\
\hline 2.18 & NDUFS6 & $\begin{array}{l}\text { NADH dehydrogenase (ubiquinone) Fe-S protein } 6,13 \\
\text { kDa (NADH-coenzyme Q reductase) }\end{array}$ & $\begin{array}{l}\text { mitochondrial electron transport, fatty acid metabolic } \\
\text { process; oxidation-reduction process }\end{array}$ & NADH dehydrogenase activity; electron carrier activity \\
\hline 2.16 & PTGER4 & prostaglandin E receptor 4 (subtype EP4) & $\begin{array}{l}\text { immune response; adenylate cyclase-modulating G-protein } \\
\text { coupled receptor signaling pathway }\end{array}$ & $\begin{array}{l}\text { prostaglandin E receptor activity; protein binding; signal } \\
\text { transducer activity; prostaglandin receptor activity }\end{array}$ \\
\hline 2.13 & IDH1 & isocitrate dehydrogenase $1(\mathrm{NADP}+)$, soluble & $\begin{array}{l}\text { glyoxylate cycle; tricarboxylic acid cycle; isocitrate } \\
\text { metabolic process; } 2 \text {-oxoglutarate metabolic process }\end{array}$ & $\begin{array}{l}\text { magnesium ion binding; isocitrate dehydrogenase activity; } \\
\text { oxidoreductase activity }\end{array}$ \\
\hline 2.13 & UQCRB & ubiquinol-cytochrome c reductase binding protein & $\begin{array}{l}\text { oxidative phosphorylation; mitochondrial electron } \\
\text { transport, oxidation-reduction process }\end{array}$ & protein binding \\
\hline 2.06 & BCKDHA & $\begin{array}{l}\text { branched chain keto acid dehydrogenase } \mathrm{E} 1 \text {, alpha } \\
\text { polypeptide }\end{array}$ & $\begin{array}{l}\text { branched-chain amino acid catabolic process; } \\
\text { oxidation-reduction process; }\end{array}$ & $\begin{array}{l}\text { alpha-ketoacid dehydrogenase activity; carboxy-lyase activity; } \\
\text { metal ion binding; oxidoreductase activity }\end{array}$ \\
\hline 2.06 & $H P G D$ & hydroxyprostaglandin dehydrogenase 15-(NAD) & $\begin{array}{l}\text { fatty acid metabolic process; prostaglandin metabolic } \\
\text { process }\end{array}$ & NAD binding; oxidoreductase activity; \\
\hline 2.06 & PIP4K2C & $\begin{array}{l}\text { phosphatidylinositol-5-phosphate 4-kinase, type II, } \\
\text { gamma }\end{array}$ & phosphatidylinositol phosphorylation & $\begin{array}{l}\text { ATP binding; nucleotide binding; kinase activity; transferase } \\
\text { activity }\end{array}$ \\
\hline 2.05 & GCLC & glutamate-cysteine ligase, catalytic subunit & $\begin{array}{l}\text { response to oxidative stress; glutamate metabolic process; } \\
\text { glutathione metabolic process }\end{array}$ & $\begin{array}{l}\text { coenzyme binding; magnesium ion binding; } \\
\text { glutamate-cysteine ligase activity; ATP binding }\end{array}$ \\
\hline 2.05 & TSTD1 & $\begin{array}{l}\text { thiosulfate sulfur transferase (rhodanese)-like domain } \\
\text { containing 1; F11 receptor }\end{array}$ & sulfide oxidation & protein binding; transferase activity \\
\hline 2.04 & $\mathrm{XDH}$ & xanthine dehydrogenase & $\begin{array}{l}\text { xanthine catabolic process; oxidation-reduction process; } \\
\text { regulation of reactive oxygen species }\end{array}$ & $\begin{array}{l}\text { iron ion binding; electron carrier activity; oxidoreductase } \\
\text { activity, metal ion binding }\end{array}$ \\
\hline 2.02 & DHODH & dihydroorotate dehydrogenase (quinone) & $\begin{array}{l}\text { nucleotide biosynthetic process; response to organic cyclic } \\
\text { compound }\end{array}$ & dehydrogenase activity; oxidoreductase activity \\
\hline 2.01 & PITPNC1 & phosphatidylinositol transfer protein, cytoplasmic 1 & phospholipid transport & $\begin{array}{l}\text { protein binding; ;ipid binding; phosphatidylinositol } \\
\text { transporter activity }\end{array}$ \\
\hline 1.99 & CYP2S1 & cytochrome P450, family 2, subfamily S, polypeptide 1 & xenobiotic metabolic process; oxidation-reduction process & $\begin{array}{l}\text { iron ion binding; oxidoreductase activity; steroid hydroxylase } \\
\text { activity }\end{array}$ \\
\hline 1.98 & RAD51 & RAD51 recombinase & DNA repair; DNA recombinase assembly & DNA binding; recombinase activity \\
\hline 1.75 & GSTK1 & glutathione S-transferase kappa 1 & $\begin{array}{l}\text { glutathione metabolic process; xenobiotic metabolic process; } \\
\text { oxidation-reduction process }\end{array}$ & $\begin{array}{l}\text { transferase activity; peroxidase activity; receptor binding; } \\
\text { oxidoreductase activity }\end{array}$ \\
\hline 1.72 & HEBP2 2 & heme binding protein 2 & $\begin{array}{l}\text { mitochondrial membrane potential; mitochondrial } \\
\text { membrane permeability; response to reactive oxygen } \\
\text { species }\end{array}$ & protein binding \\
\hline 1.64 & POR & P450 (cytochrome) oxidoreductase & xenobiotic metabolic process; response to nutrient & enzyme binding; hydrolase activity; electron transfer activity \\
\hline 1.63 & CYP4Z1 & cytochrome P450, family 4, subfamily Z, polypeptide 1 & oxidation-reduction process & $\begin{array}{l}\text { iron ion binding; heme binding; aromatase activity; } \\
\text { oxidoreductase activity; metal ion binding }\end{array}$ \\
\hline 1.52 & PEX11A & peroxisomal biogenesis factor 11 alpha & peroxisome organization; lipid metabolic process & protein binding; protein homodimerization activity \\
\hline 1.51 & $\mathrm{COX} 6 \mathrm{C}$ & cytochrome $\mathrm{c}$ oxidase subunit VIc & $\begin{array}{l}\text { mitochondrial electron transport; hydrogen ion } \\
\text { transmembrane transport }\end{array}$ & oxidase activity \\
\hline-1.52 & NOXA1 & NADPH oxidase activator 1 & $\begin{array}{l}\text { superoxide metabolic process; regulation of hydrogen } \\
\text { peroxide metabolic process }\end{array}$ & NADPH oxidase activity; enzyme binding \\
\hline
\end{tabular}


Table 2. Cont.

\begin{tabular}{|c|c|c|c|c|}
\hline \multicolumn{5}{|c|}{ siNFKB MDA-MB-231 } \\
\hline Fold Change & Gene Symbol & Description & GO Biological Process & GO Molecular Function \\
\hline-1.55 & NOS1AP & nitric oxide synthase 1 (neuronal) adaptor protein & nitric oxide biosynthetic process; apoptotic process & nitric-oxide synthase binding \\
\hline-1.6 & СУР2U1 & cytochrome P450, family 2, subfamily U, polypeptide 1 & $\begin{array}{l}\text { xenobiotic metabolic process; arachidonic acid metabolic } \\
\text { process; oxidation-reduction process }\end{array}$ & iron ion binding; oxidoreductase activity \\
\hline-1.65 & GPX3 & glutathione peroxidase 3 (plasma) & $\begin{array}{l}\text { response to lipid hydroperoxide; oxidation-reduction } \\
\text { process; response to oxidative stress }\end{array}$ & $\begin{array}{l}\text { glutathione peroxidase activity; transcription factor binding } \\
\text { selenium binding; oxidoreductase activity }\end{array}$ \\
\hline-1.67 & GSTP1 & glutathione S-transferase pi 1 & $\begin{array}{l}\text { response to reactive oxygen species; glutathione metabolic } \\
\text { process; xenobiotic metabolic process }\end{array}$ & $\begin{array}{l}\text { glutathione transferase activity; nitric oxide binding; } \\
\text { transferase activity }\end{array}$ \\
\hline-1.67 & MT1A & metallothionein $1 \mathrm{~A}$ & $\begin{array}{l}\text { cellular response to cadmium ion; cellular response to zinc } \\
\text { ion }\end{array}$ & protein binding; metal ion binding \\
\hline-1.73 & GSTT2 & $\begin{array}{l}\text { glutathione S-transferase theta 2; glutathione S-transferase } \\
\text { theta } 2 \mathrm{~B} \text { (gene/pseudogene) }\end{array}$ & glutathione metabolic process; xenobiotic metabolic process; & $\begin{array}{l}\text { glutathione transferase activity; transferase activity; protein } \\
\text { binding }\end{array}$ \\
\hline-1.74 & MSRB3 & methionine sulfoxide reductase B3 & $\begin{array}{l}\text { response to oxidative stress; protein repair; } \\
\text { oxidation-reduction process }\end{array}$ & zinc ion binding; oxidoreductase activity \\
\hline-1.76 & ARG2 & arginase 2 & $\begin{array}{l}\text { urea cycle; arginine metabolic process; nitric oxide } \\
\text { biosynthetic process }\end{array}$ & arginase activity; metal ion binding; hydrolase activity \\
\hline-2.56 & GSTM1 & glutathione S-transferase mu 1 & glutathione metabolic process; xenobiotic metabolic process & glutathione transferase activity; enzyme binding \\
\hline
\end{tabular}




\begin{tabular}{|c|c|c|c|c|}
\hline \multicolumn{5}{|c|}{ siNFKB HCC-1954 } \\
\hline Fold Change & Gene Symbol & Description & GO Biological Process & GO Molecular Function \\
\hline 1.78 & HSD17B2 & hydroxysteroid (17-beta) dehydrogenase 2 & steroid biosynthetic process; oxidation-reduction process & $\begin{array}{l}\text { estradiol 17-beta-dehydrogenase activity; testosterone } \\
\text { dehydrogenase activity }\end{array}$ \\
\hline 1.7 & COX11P1 & $\begin{array}{l}\text { COX11 cytochrome c oxidase assembly homolog (yeast) } \\
\text { pseudogene } 1\end{array}$ & $\begin{array}{l}\text { mitochondrial electron transport, hydrogen ion } \\
\text { transmembrane transport }\end{array}$ & cytochrome-c oxidase activity \\
\hline 1.64 & BRCA1 & breast cancer 1 , early onset & $\begin{array}{l}\text { DNA repair, double-strand break repair via homologous } \\
\text { recombination }\end{array}$ & DNA binding, ligase activity \\
\hline 1.58 & FAR1 & fatty acyl CoA reductase 1 & $\begin{array}{l}\text { glycerophospholipid biosynthetic process; } \\
\text { oxidation-reduction process }\end{array}$ & $\begin{array}{l}\text { fatty-acyl-CoA reductase (alcohol-forming) activity; } \\
\text { oxidoreductase activity }\end{array}$ \\
\hline 1.57 & NUDT4 & $\begin{array}{l}\text { nudix (nucleoside diphosphate linked moiety X)-type } \\
\text { motif } 4\end{array}$ & $\begin{array}{l}\text { cyclic nucleotide metabolic process, inositol phosphate } \\
\text { metabolic process }\end{array}$ & $\begin{array}{l}\text { hydrolase activity, endopolyphosphatase activity, protein } \\
\text { binding }\end{array}$ \\
\hline 1.56 & $H P G D$ & hydroxyprostaglandin dehydrogenase 15-(NAD) & $\begin{array}{l}\text { fatty acid metabolic process, prostaglandin metabolic } \\
\text { process }\end{array}$ & $\begin{array}{l}\text { NAD binding, prostaglandin E receptor activity, } \\
\text { oxidoreductase activity }\end{array}$ \\
\hline 1.54 & PEX1 & peroxisomal biogenesis factor 1 & $\begin{array}{l}\text { peroxisome membrane biogenesis; cellular lipid metabolic } \\
\text { process }\end{array}$ & protein binding; protein homodimerization activity \\
\hline 1.53 & DHRSTC & dehydrogenase/reductase (SDR family) member 7C & oxidation-reduction process & retinol dehydrogenase activity; oxidoreductase activity \\
\hline 1.52 & $\mathrm{XRCC4}$ & $\begin{array}{l}\text { X-ray repair complementing defective repair in Chinese } \\
\text { hamster cells } 4\end{array}$ & DNA repair, double-strand break repair & DNA binding; protein binding; ligase activity \\
\hline 1.51 & $\mathrm{COX} 8 \mathrm{C}$ & cytochrome $\mathrm{c}$ oxidase subunit VIIIC & $\begin{array}{l}\text { mitochondrial electron transport, hydrogen ion } \\
\text { transmembrane transport }\end{array}$ & cytochrome-c oxidase activity \\
\hline 1.51 & PTGDS & prostaglandin D2 synthase $21 \mathrm{kDa}$ (brain) & $\begin{array}{l}\text { prostaglandin biosynthetic process, fatty acid metabolic } \\
\text { process }\end{array}$ & transporter activity, retinoid binding, fatty acid binding \\
\hline-1.51 & PDLIM3 & PDZ and LIM domain 3 & actin filament organization & cytoskeletal protein binding; zinc ion binding \\
\hline-1.52 & PDK2 & pyruvate dehydrogenase kinase, isozyme 2 & glucose metabolic process, protein phosphorylation & $\begin{array}{l}\text { protein serine/threonine kinase activity, pyruvate } \\
\text { dehydrogenase kinase activity }\end{array}$ \\
\hline-1.66 & TCAP & titin-cap & cardiac muscle contraction, protein complex assembly & titin binding; ion channel binding \\
\hline-1.72 & DHRS12 & dehydrogenase/reductase (SDR family) member 12 & oxidation-reduction process & oxidoreductase activity \\
\hline-1.75 & HSD17B4 & hydroxysteroid (17-beta) dehydrogenase 4 & fatty acid metabolic process, fatty acid beta-oxidation & oxidoreductase activity \\
\hline-1.76 & CYP4Z2P & $\begin{array}{l}\text { cytochrome P450, family } 4 \text {, subfamily Z, polypeptide } 2 \text {, } \\
\text { pseudogene }\end{array}$ & oxidation-reduction process & iron ion binding; oxidoreductase activity, heme binding \\
\hline-1.82 & LIPK & lipase, family member $\mathrm{K}$ & lipid catabolic process; lipid metabolic process & hydrolase activity \\
\hline-1.88 & MT-TM & mitochondrially encoded tRNA methionine & tRNA Aminoacylation & catalytic activity \\
\hline
\end{tabular}




\begin{tabular}{|c|c|c|c|c|}
\hline \multicolumn{5}{|l|}{ SiNFKB MCF-7 } \\
\hline Fold Change & Gene Symbol & Description & GO Biological Process & GO Molecular Function \\
\hline 1.84 & NDUFS7 & $\begin{array}{l}\text { NADH dehydrogenase (ubiquinone) Fe-S protein 7, } 20 \\
\text { kDa (NADH-coenzyme Q reductase) }\end{array}$ & $\begin{array}{l}\text { mitochondrial electron transport; oxidation-reduction } \\
\text { process }\end{array}$ & NADH dehydrogenase activity; oxidoreductase activity \\
\hline 1.75 & PTGS1 & $\begin{array}{l}\text { prostaglandin-endoperoxide synthase } 1 \text { (prostaglandin } \\
\text { G/H synthase and cyclooxygenase) }\end{array}$ & $\begin{array}{l}\text { prostaglandin biosynthetic process; fatty acid metabolic } \\
\text { process }\end{array}$ & $\begin{array}{l}\text { peroxidase activity; lipid binding; heme binding; metal } \\
\text { ion binding; dioxygenase activity; oxidoreductase activity }\end{array}$ \\
\hline 1.67 & PLCD1 & phospholipase C, delta 1 & $\begin{array}{l}\text { phospholipid metabolic process; inositol phosphate } \\
\text { metabolic process }\end{array}$ & $\begin{array}{l}\text { calcium ion binding; phosphoric diester hydrolase } \\
\text { activity; phosphatidylserine binding }\end{array}$ \\
\hline 1.61 & CYB561A3 & cytochrome b561 family, member A3 & oxidation-reduction process & $\begin{array}{l}\text { protein binding; oxidoreductase activity; metal ion } \\
\text { binding }\end{array}$ \\
\hline 1.6 & PLA2G1B & phospholipase A2, group IB (pancreas) & activation of MAPK activity; fatty acid biosynthetic process & $\begin{array}{l}\text { phospholipase activity; receptor binding; calcium ion } \\
\text { binding; hydrolase activity; metal ion binding }\end{array}$ \\
\hline 1.59 & PDE3B & phosphodiesterase 3B, cGMP-inhibited & cAMP catabolic process; glucose homeostasis & metal ion binding; phosphoric diester hydrolase activity \\
\hline 1.57 & FTHL17 & ferritin, heavy polypeptide-like 17 & iron ion transport & ferric iron binding; metal ion binding \\
\hline 1.57 & $L P O$ & lactoperoxidase & $\begin{array}{l}\text { response to oxidative stress; hydrogen peroxide catabolic } \\
\text { process; oxidation-reduction process }\end{array}$ & $\begin{array}{l}\text { heme binding; metal ion binding; peroxidase activity; } \\
\text { oxidoreductase activity }\end{array}$ \\
\hline 1.57 & TXNP6 & thioredox & pseudogene 6 & response to oxidative stress \\
\hline 1.56 & PLA2G15 & phospholipase A2, group XV & phospholipid metabolic process & phospholipase activity; hydrolase activity \\
\hline 1.54 & PLD6 & phospholipase D family, member 6 & $\begin{array}{l}\text { phospholipid metabolic process; nucleic acid } \\
\text { phosphodiester bond hydrolysis }\end{array}$ & $\begin{array}{l}\text { endoribonuclease activity; metal ion binding; } \\
\text { endonuclease activity; hydrolase activity }\end{array}$ \\
\hline 1.52 & MSRB1 & methionine sulfoxide reductase $B 1$ & $\begin{array}{l}\text { response to oxidative stress; protein repair; } \\
\text { oxidation-reduction process }\end{array}$ & $\begin{array}{l}\text { zinc ion binding; oxidoreductase activity; metal ion } \\
\text { binding }\end{array}$ \\
\hline 1.51 & PEX16 & peroxisomal biogenesis factor 16 & protein targeting to peroxisome; peroxisome organization & protein binding \\
\hline 1.5 & PRDX5 & peroxiredoxin 5 & $\begin{array}{l}\text { response to oxidative stress; inflammatory response; } \\
\text { apoptotic process }\end{array}$ & $\begin{array}{l}\text { thioredoxin peroxidase activity; antioxidant activity; } \\
\text { receptor binding; oxidoreductase activity }\end{array}$ \\
\hline 1.5 & TP53RK & TP53 regulating kinase & tRNA modification; protein phosphorylation; p53 binding & $\begin{array}{l}\text { protein serine/threonine kinase activity; ATP binding; } \\
\text { hydrolase activity; nucleotide binding }\end{array}$ \\
\hline-1.51 & CYB5R4 & cytochrome b5 reductase 4 & $\begin{array}{l}\text { superoxide metabolic process; glucose homeostasis; } \\
\text { oxidation-reduction process; NADP metabolic process }\end{array}$ & oxidoreductase activity; heme binding; metal ion binding \\
\hline-1.53 & PEX1 & peroxisomal biogenesis factor 1 & protein targeting to peroxisome; peroxisome organization & protein binding; ATP binding; nucleotide binding \\
\hline-1.54 & DECR1 & 2,4-dienoyl CoA reductase 1 , mitochondrial & fatty acid metabolic process; oxidation-reduction process & NADPH binding; oxidoreductase activity \\
\hline-1.56 & TXNDC9 & thioredoxin domain containing 9 & cell redox homeostasis; biological process & protein binding \\
\hline-1.61 & SEPP1 & selenoprotein $\mathrm{P}$, plasma, 1 & $\begin{array}{l}\text { selenium compound metabolic process; response to } \\
\text { oxidative stress }\end{array}$ & selenium binding \\
\hline-1.62 & OXR1 & oxidation resistance 1 & response to oxidative stress; oxidation-reduction process & protein binding; oxidoreductase activity \\
\hline-1.63 & $T M X 1$ & thioredoxin-related transmembrane protein 1 & $\begin{array}{l}\text { protein folding; cell redox homeostasis; oxidation-reduction } \\
\text { process }\end{array}$ & disulfide oxidoreductase activity \\
\hline-1.64 & PLCB4 & phospholipase C, beta 4 & lipid metabolic process & $\begin{array}{l}\text { calcium ion binding; phosphoric diester hydrolase } \\
\text { activity; phospholipase } \mathrm{C} \text { activity }\end{array}$ \\
\hline
\end{tabular}




\begin{tabular}{|c|c|c|c|c|}
\hline \multicolumn{5}{|l|}{ siNFKB MCF-7 } \\
\hline Fold Change & Gene Symbol & Description & GO Biological Process & GO Molecular Function \\
\hline-1.81 & CYCS & cytochrome c, somatic & mitochondrial electron transport; apoptotic process & iron ion binding; electron transfer activity; heme binding \\
\hline-2.1 & PIK3CA & $\begin{array}{l}\text { phosphatidylinositol-4,5-bisphosphate 3-kinase, catalytic } \\
\text { subunit alpha }\end{array}$ & $\begin{array}{l}\text { glucose metabolic process; 1-phosphatidylinositol-3-kinase } \\
\text { activity }\end{array}$ & $\begin{array}{l}\text { transferase activity; protein serine/threonine kinase } \\
\text { activity; ATP binding }\end{array}$ \\
\hline-2.19 & MDM1 & Mdm1 nuclear protein homolog (mouse) & p53 binding protein; regulation of centriole replication & protein binding \\
\hline-2.76 & ATM & $\begin{array}{l}\text { ATM serine/threonine kinase; nuclear protein, } \\
\text { ataxia-telangiectasia locus }\end{array}$ & DNA repair; telomere maintenance & $\begin{array}{l}\text { transferase activity; DNA binding; protein } \\
\text { serine/threonine kinase activity }\end{array}$ \\
\hline-2.81 & РIКЗС2A & $\begin{array}{l}\text { phosphatidylinositol-4-phosphate 3-kinase, catalytic } \\
\text { subunit type } 2 \text { alpha }\end{array}$ & phosphatidylinositol biosynthetic process & phosphotransferase activity; ATP binding \\
\hline-2.85 & ATR & ATR serine/threonine kinase & DNA repair; cell cycle; DNA damage checkpoint & $\begin{array}{l}\text { transferase activity; DNA binding; protein } \\
\text { serine/threonine kinase activity }\end{array}$ \\
\hline-3.04 & NUDT12 & $\begin{array}{l}\text { nudix (nucleoside diphosphate linked moiety X)-type } \\
\text { motif } 12\end{array}$ & NADP catabolic process & metal ion binding; hydrolase activity \\
\hline-3.18 & CYP4F30P & cytochrome P450, family 4, subfamily F, polypeptide 30 & oxidation-reduction process & oxidoreductase activity \\
\hline-3.57 & PYROXD1 & pyridine nucleotide-disulfide oxidoreductase domain 1 & oxidation-reduction process & protein binding; oxidoreductase activity \\
\hline-3.82 & $B R C A 2$ & breast cancer 2, early onset & $\begin{array}{l}\text { double-strand break repair via homologous recombination; } \\
\text { DNA synthesis involved in DNA repair }\end{array}$ & $\begin{array}{l}\text { protease binding; histone acetyltransferase activity; } \\
\text { protein binding; } \mathrm{H} 3 \text { histone acetyltransferase activity; } \mathrm{H} 4 \\
\text { histone acetyltransferase activity; gamma-tubulin binding; } \\
\text { DNA binding }\end{array}$ \\
\hline-3.88 & ATRX & alpha thalassemia/mental retardation syndrome $\mathrm{X}$-linked & DNA repair; nucleosome assembly & $\begin{array}{l}\text { chromatin binding; helicase activity; DNA binding; DNA } \\
\text { helicase activity; helicase activity }\end{array}$ \\
\hline
\end{tabular}


In silico analysis of these results showed that the genes that were altered in siNF-KB MDA-MB-231 were related to redox metabolism, such as aldo-keto reduction (AKR1B10, AKR1C2), glutathione metabolism (GPX2, GPX3, GSTM1, GSTT1, GSTT2, GSTK1, GSTP1), NADH dehydrogenase activity (NDUFB9, NDUFS6), the PI3K family (PIK3C2B, PIP4K2C, PITPNC1), prostaglandin signaling (PTGER4, PTGES, PTGFRN, PTGS2), and the cytochrome P450 family (POR, CYP2S1, CYP2UI, CYP4B1, CYP4Z1, CYB5A). In addition, the potent hydroxylase xanthine dehydrogenase $(X D H)$ was up-regulated, revealing an antioxidant effect. The altered genes in siNF- KB HCC-1954 were mainly related to the COX family (COX11P1, COX8C) and fatty acid metabolism (FAR1, LIPK). Finally, we identified members of the PI3K family (PIK3C2A, PIK3CA) and phospholipid metabolism (PLCD1, PLA2G1B, $P L A 2 G 15, P L D G, P L C B 4)$ as the main modified genes in siNF-KB MCF-7. In addition, important genes related to the response to OS were found among the altered genes in siNF-KB MCF-7, such as OXR1 and TMX1. Although none of the altered genes were common to all lists of redox metabolism-related

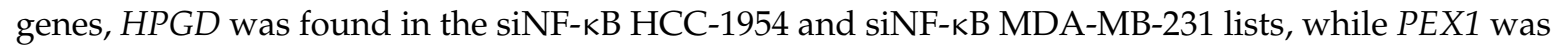
found in the siNF- $\mathrm{B}$ HCC-1954 and siNF- $\mathrm{kB}$ MCF-7 lists (as presented in the Venn diagram, Figure 2). Interestingly, DNA repair members related to the response to OS were identified in all three altered gene lists: up-regulation of TP63 and RAD51 in siNF-KB MDA-MB-231, up-regulation of $B R C A 1, R B 1$ and XRCC4 in siNF-kB HCC-1954, and down-regulation of BRCA2, ATM and ATR in siNF-kB MCF-7.

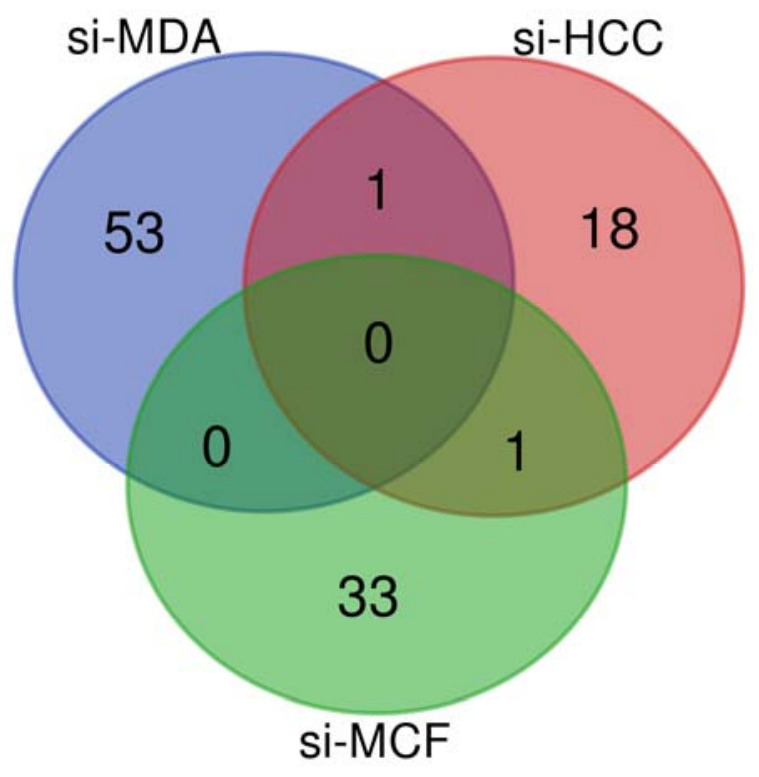

Figure 2. Venn diagram based on the lists of altered genes related to redox metabolism found in breast cancer models silenced for NF-kB/p65 compared with their scramble counterparts. Si-MDA: NF-кB/p65-silenced MDA-MB-231; si-HCC: NF-кB/p65-silenced HCC-1954; and si-MCF: NF-kB/p65-silenced MCF-7.

To confirm the microarray results, we selected some altered genes for mRNA level evaluation by RT-qPCR. As shown in Figure 3, we confirmed the microarray data: TP63, GPX2, HPGD were up-regulated and $A R G 2$ was down-regulated in siNF-кB MDA-MB-231 (Figure 3A); BRCA1, PEX1, HPGD and COX8C were up-regulated in siNF- $\mathrm{BB}$ HCC-1954 (Figure 3B); and BRCA2, PEX1, OXR1 and TMX1 were down-regulated in siNF-KB MCF-7 (Figure 3C). 


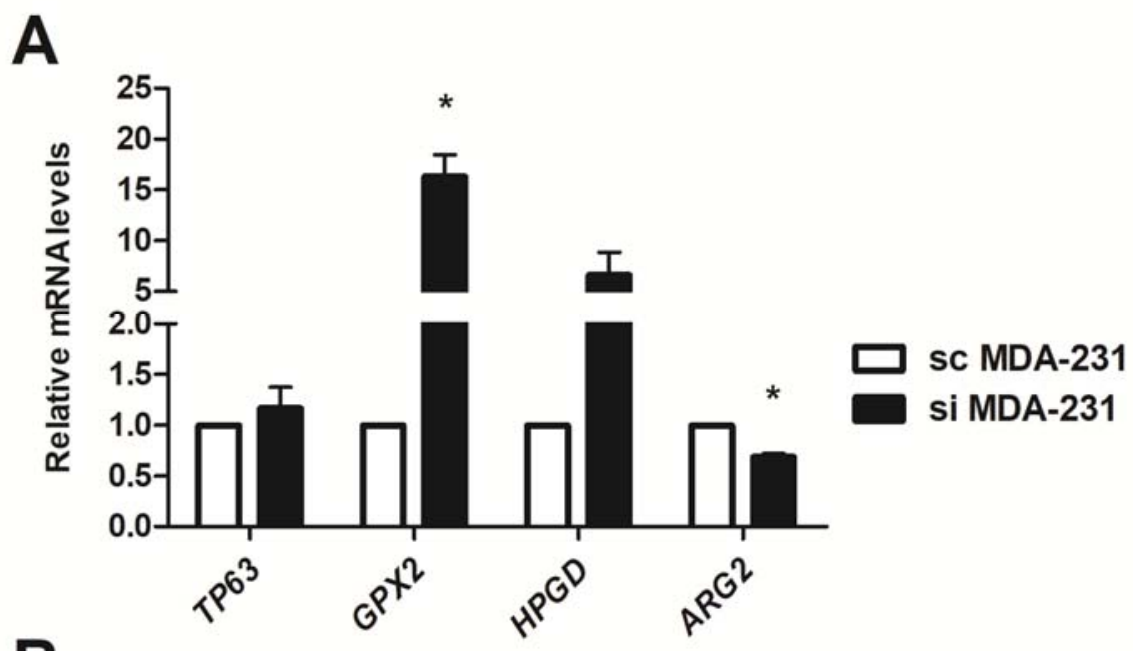

B
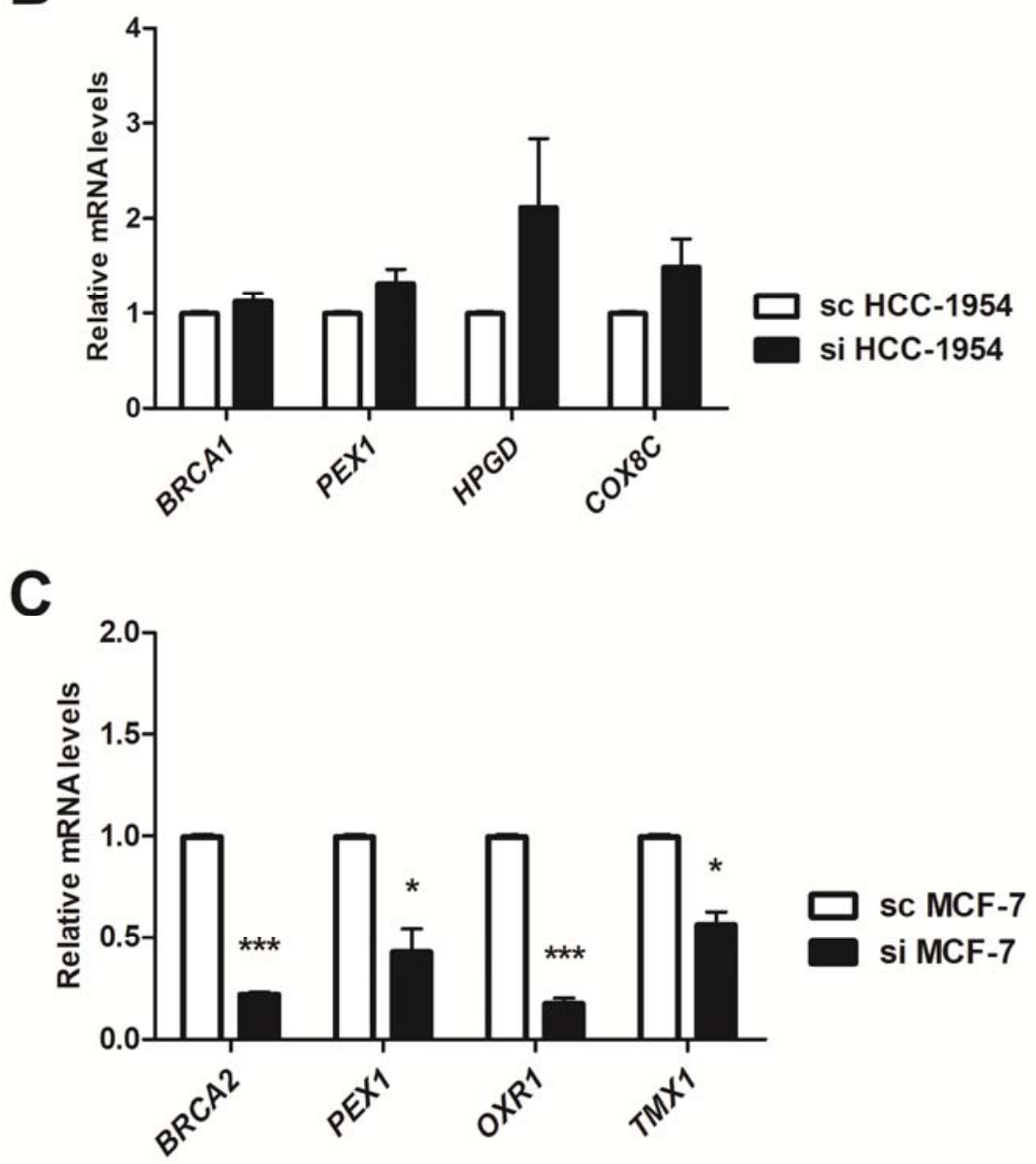

Figure 3. Relative expression by real time PCR (qPCR) of differentially expressed genes in the microarray analysis after NF- $\mathrm{B}$ genetic silencing. The mRNA levels were assessed in MDA-MB-231 (A); HCC-1954 (B) and MCF-7 (C) cells, comparing the NF-kB-silenced condition (si) with the Scramble (sc) counterpart. Data are expressed as the means and standard errors of the means. ${ }^{*}$ : $p$-value $<0.05$; **: $p<0.01 ;{ }^{* * *}: p<0.001$. 


\subsection{Oxidative Stress Analyses}

To evaluate the relationship between NF- $\mathrm{kB} / \mathrm{p} 65$ and OS in each BC subtype models, we treated the cells with the NF- $\mathrm{kB}$ inhibitor DHMEQ as described previously [18]. Initially, we evaluated the basal levels of lipid peroxidation, thiol, and NO in untreated cells (Figure S1). Regarding the thiol content, we observed that all BC cells presented distinct basal levels. DHMEQ treatment resulted in reduced thiol in MCF-7 cells after both durations of exposure (from $55.83 \pm 1.5 \mu \mathrm{M}$ to $43.05 \pm 1.67 \mu \mathrm{M}$ in $24 \mathrm{~h}, p=0.0048$, Figure $4 \mathrm{~A}$, and from $54.3 \pm 2.5 \mu \mathrm{M}$ to $39.72 \pm 3.95 \mu \mathrm{M}$ in $48 \mathrm{~h}, p=0.0357$, Figure 4B). For HCC-1954 cells, DHMEQ treatment led to an increased thiol content only after $24 \mathrm{~h}$ of exposure (from $47.7 \pm 1.35 \mu \mathrm{M}$ in controls to $53.16 \pm 1.27 \mu \mathrm{M}$ in treated cells, $p=0.0420$, Figure $4 \mathrm{C}$ ). For MDA-MB-231 cells, DHMEQ reduced the thiol content after $24 \mathrm{~h}$ (from $18.58 \pm 0.72 \mu \mathrm{M}$ in controls to $7.84 \pm 0.55 \mu \mathrm{M}$ in treated cells, $p=0.003$, Figure $4 \mathrm{E})$, while it augmented the thiol content after $48 \mathrm{~h}$ of exposure $(14.4 \pm 0.64 \mu \mathrm{M}$ in controls and $20.45 \pm 0.82 \mu \mathrm{M}$ in the DHMEQ group, $p=0.0044$, Figure 4F).

A

MCF-7 24h

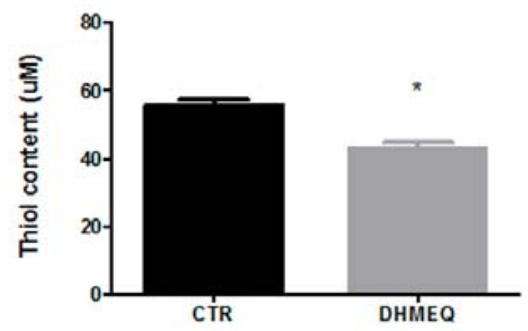

$\mathrm{C}$

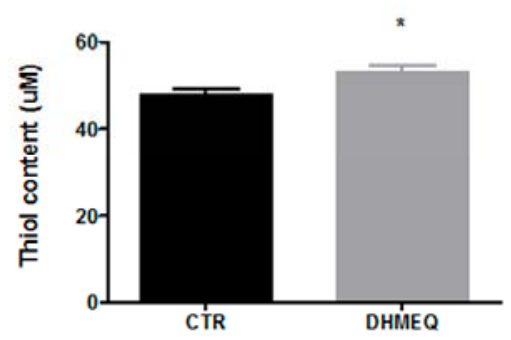

$\mathrm{E}$

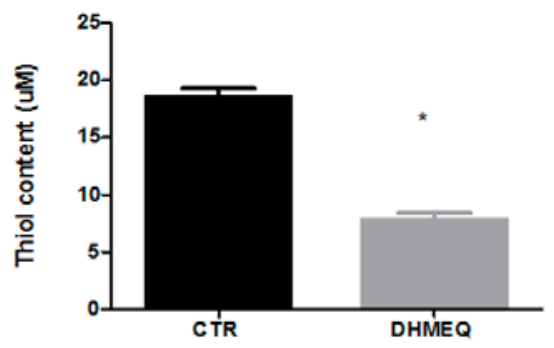

$\mathrm{B}$

MCF-7 48h

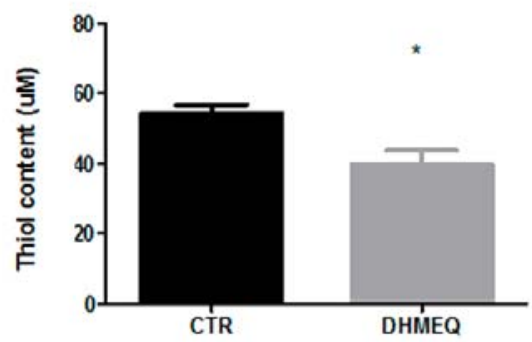

D

HCC-1954 48h

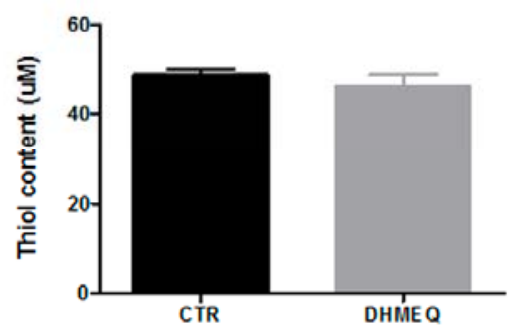

F

MDA-MB-231 48h

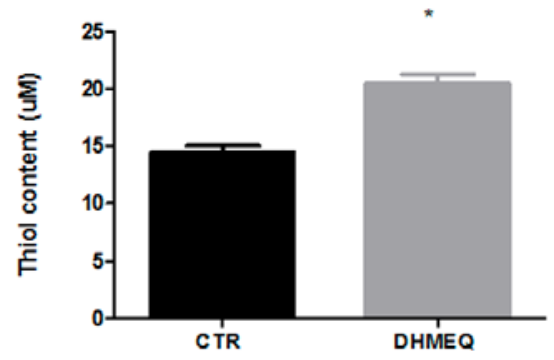

Figure 4. Thiol content. MCF-7 (A,B), HCC (C,D) and MDA-MB231 (E,F) cells treated (DHMEQ column) or not (CTR column) with NF-kB inhibitor for 24 or $48 \mathrm{~h}$. Data are expressed as the means and standard errors of the means. * indicates statistical significance $(p<0.05)$.

Concerning the lipid peroxidation profile, it was noted that after $24 \mathrm{~h}$ of DHMEQ treatment, MCF-7 cells exhibited higher lipid peroxidation than the control (Figure $5 \mathrm{~A}, p<0.001$ ), and this profile 
was reversed after $48 \mathrm{~h}$ (Figure 5B, $p<0.001$ ). In HCC-1954 cells, DHMEQ treatment reduced lipid peroxidation after both periods of exposure (Figure 5C,D, $p<0.001$ ). In contrast, MDA-MB231 cells presented enhanced lipid peroxidation after DHMEQ exposure after both durations of treatment (Figure $4 \mathrm{E}, \mathrm{F}, p<0.001)$.
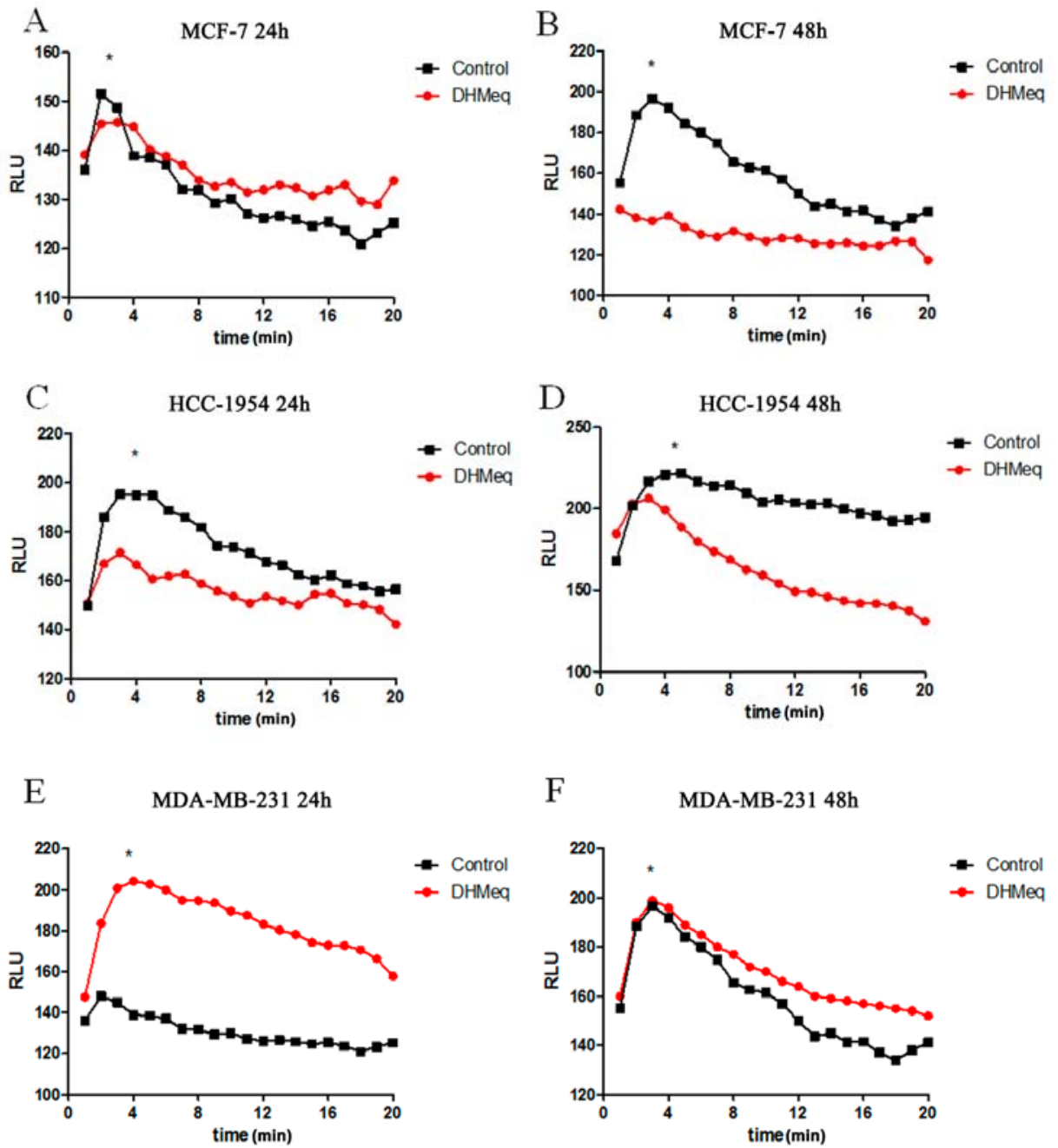

Figure 5. Lipid peroxidation profile. MCF-7 (A,B), HCC-1954 (C,D) and MDA-MB231 (E,F) cells treated or not with NF- $\mathrm{kB}$ inhibitor for 24 or $48 \mathrm{~h}$. Data are expressed as the means. ${ }^{*}$ indicates statistical significance $(p<0.05)$. Time $(\mathrm{min})$.

The NO measurements indicated a reduction after $24 \mathrm{~h}$ of DHMEQ inhibition for MCF-7 (from $80.64 \pm 1.43 \mu \mathrm{M}$ in the control to $43.17 \pm 1.82 \mu \mathrm{M}$ in the DHMEQ group, $p<0.001$, Figure $6 \mathrm{~A}$ ), followed by augmentation after $48 \mathrm{~h}$ of exposure (from $60.51 \pm 1.06 \mu \mathrm{M}$ in controls to $80 \pm 2.18 \mu \mathrm{M}$ in the DHMEQ group, $p=0.0013$, Figure 6B). In HCC-1954 cells, only the 24-h treatment with DHMEQ altered NO (from $47.7 \pm 1.35 \mu \mathrm{M}$ in the control to $53.16 \pm 1.26 \mu \mathrm{M}$ in DHMEQ, $p=0.0420$, Figure $6 \mathrm{C}$ ). MDA-MB 231 cells did not show altered NO levels under any condition (Figure 6E,F). 
A

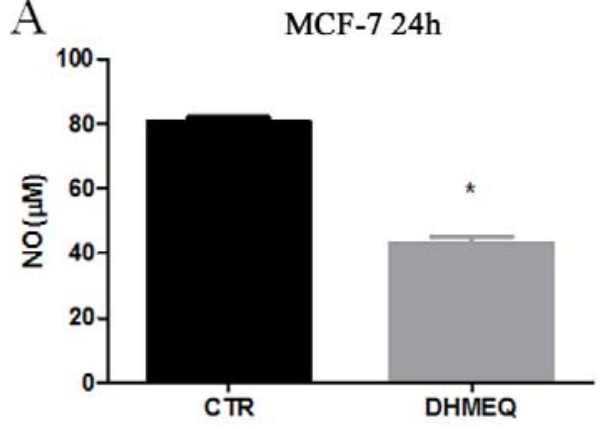

C

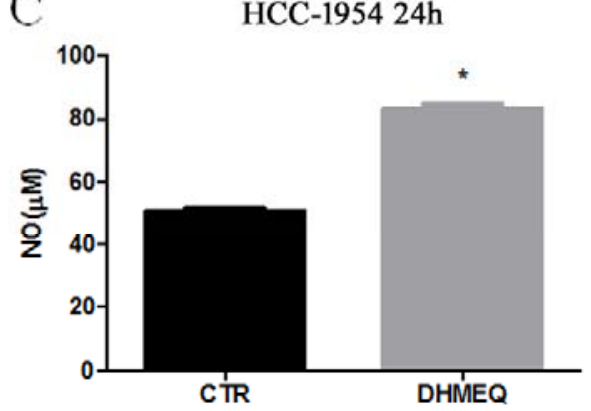

$\mathrm{E}$

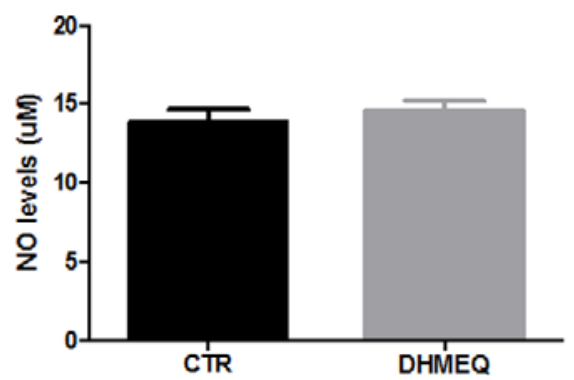

B

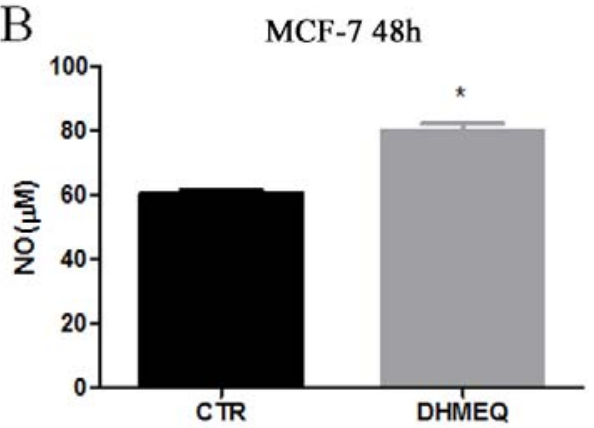

D

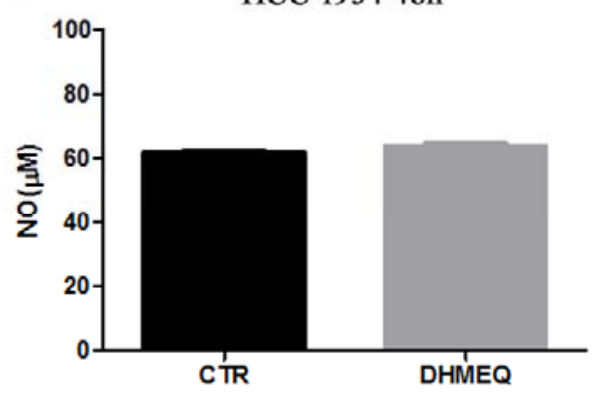

$\mathrm{F}$

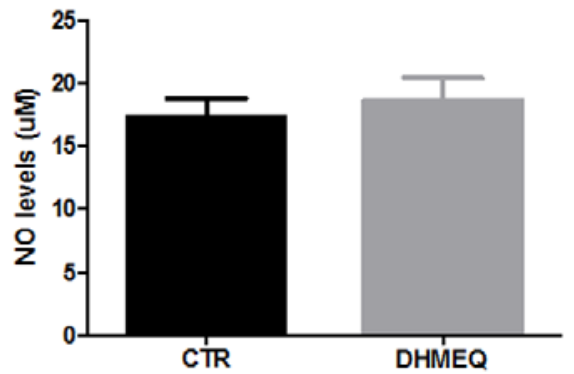

Figure 6. Nitrite as an estimate of NO levels. MCF-7 (A,B), HCC (C,D) and MDA-MB231 (E,F) cells treated (DHMEQ column) or not (CTR column) with NF- $\mathrm{kB}$ inhibitor for 24 or $48 \mathrm{~h}$. Data are expressed as the means and standard errors of the means. ${ }^{*}$ indicates statistical significance $(p<0.05)$.

\section{Discussion}

Oxidative stress (OS) is an indispensable condition to ensure genomic instability in cancer cells [26-29]. Thus, a redox imbalance represents an important factor for BC carcinogenesis and prognosis and is frequently associated with pro-inflammatory conditions [24,30-32]. Although a correlation between NF- $\mathrm{kB}$ and OS has been reported in cancer [33,34], its role in BC intrinsic groups has not been reported to date.

In the present study, we showed that NF-kB silencing altered the expression of a large number of genes in distinct subtypes of $\mathrm{BC}$ cells, some of which were shown to be important members of the redox balance through pathway enrichment analysis and gene ontology information. Relevant members involved in glutathione metabolism, prostaglandins, cytochrome P450 and cyclooxygenase were differentially expressed after NF- $\mathrm{KB}$ silencing in the distinct $\mathrm{BC}$ subtypes, suggesting a relationship between the redox balance and this transcription factor in such cells.

When we analyzed individually each differentially expressed gene list, we observed that only peroxisomal biogenesis factor (PEX) 1 and 15-hydroxyprostaglandin dehydrogenase (HPGD) were differentially expressed in more than one list. PEX1 was down-regulated in NF-KB-silenced MCF-7 and 
up-regulated in NF-kB-silenced HCC-1954. In these findings, because PEX1 levels are in accordance with NF-KB levels, PEX1 may play a pro-tumorigenic role in MCF-7 cells, which is supported by Bartling et al. [35] and Pang et al. [36], in opposition to what is observed in NF-kB-silenced HCC-1954 cells, as proposed by Lee et al. [37]. Different from PEX1, there was an accordance between HPGD up-regulation in NF-KB-silencing for MDA-MB-231 and HCC-1954, showing that HPGD may play a tumor suppressor role, as reported by Pham et al. [38] and Thiel et al. [39]. Additionally, high expression of HPGD is pointed out as favorable prognostic marker in renal cancer by The Human Protein Atlas [40].

Consequently, we validated the microarray dataset focusing on OS. To achieve this goal, we performed biochemical analyses assessing the antioxidant capacity, lipid peroxidation profile and $\mathrm{NO}$ status in $\mathrm{BC}$ cell subtypes and correlated such parameters with the presence or absence of NF- $\mathrm{KB}$. Among the current small molecules able to inhibit NF- $\mathrm{kB}$, DHMEQ is known for its effectiveness and specificity [41,42]. It directly binds to NF- $\mathrm{kB} / \mathrm{p} 65$ and represses its nuclear translocation as well as DNA-binding activity [43], in addition to showing interesting effects against several tumors, including breast cancer $[11,18,44]$. Thus, the activity of this molecule as an NF- $\mathrm{KB} / \mathrm{p} 65$ inhibitor was utilized in our study.

First, we evaluated the basal levels of untreated cells. Lipid peroxidation was similar along time ( $24 \mathrm{~h}$ and $48 \mathrm{~h}$ ). HCC-1954 cells were the most oxidized lineage when compared to both MCF-7 and MDA-MB-231, indicating that HER2 amplification may promote this event. Studies showed that cells overexpressing HER2 exhibit more lipid peroxidation than other subtype models [45], although patients carrying HER2-amplified tumors showed reduced lipid peroxidation in plasma. This contradiction has been discussed by other authors, and they suggested that the sustained oxidative stress may favor the change HER2-positive phenotype to a HER2-negative [46]. Both MCF-7 and MDA-MB-231 exhibited a very similar pattern of lipid peroxidation (Figure S1), although experimental and clinical studies have proposed that ER positive tumors are inducers of oxidative stress and lipid peroxidation [47-49], while others have reported that some oxidative stress-related markers are generally down-regulated in TNBC [50,51]. MDA-MB-231 also presented low basal levels of NO and thiol content when compared to the other cells, with enhanced depletion of antioxidant content after $48 \mathrm{~h}$ (Figure S1).

Regarding the NF- $\mathrm{KB}$-inhibition effects, our data revealed completely distinct oxidation statuses of the three studied cell lines. MCF-7 cells, in which the main regulatory axis is ER signaling, displayed higher antioxidant capacity at basal levels when compared to the other cells, as observed by the attenuated lipid peroxidation profile and high thiol content. Such a profile may be related to the antioxidant activity of estrogen-induced signaling, which blocks reactive oxygen species (ROS) [52] and increases NO synthesis [53]. Furthermore, microarray data from MCF-7 cells revealed a few relevant members of the antioxidant response, indicating that ER signaling should explain the observed redox status. Despite the power of estrogen-induced signaling, our results indicated that the initial NF- $\mathrm{KB}$ inhibition observed after $24 \mathrm{~h}$ affected the redox status of MCF-7 cells, suggesting that the integrity of this axis might contribute to the redox stability of luminal cancer. Despite the mutual NF- $\mathrm{KB} / \mathrm{ER}$ interaction in MCF-7 cells, ER signaling seemed to predominate in this case [54]. Sustained NF- $\mathrm{KB}$ inhibition seemed to potentiate the antioxidant capacity of MCF-7, since lipid peroxidation was even more attenuated after $48 \mathrm{~h}$ of treatment, in association with augmented NO. It has been demonstrated that NO can inhibit NF- $\mathrm{kB}$ binding to DNA by modifying the transcription factor structure [55], impairing its pro-oxidant capacity.

HER2-amplified cells demonstrated an intermediary oxidative profile when compared to the other BC cells investigated at basal levels, potentially because HER2 overexpression attenuates OS in breast cancer [32,49]. The 24-h NF-KB inhibition simultaneously augmented the thiol content and reduced lipid peroxidation, revealing a role for this transcription factor in the regulation of the OS of HER2-amplified cells. HER2 amplification is known to activate NF- $\mathrm{KB}$ in breast cancer through its canonical pathway [15], consequently triggering OS-related responses [56]. Thus, when we silenced NF- $\mathrm{kB}$ in these cells, this pro-oxidant arm was probably restricted, culminating in reduced OS. 
After $48 \mathrm{~h}$, the attenuated oxidative profile was maintained, as noted by the reduced lipid peroxidation profile exhibited by DHMEQ-treated cells.

TNBC cells showed lower levels of antioxidants at basal levels, exhibiting a pro-oxidant status after $24 \mathrm{~h}$ of DHMEQ exposure that was completely reversed after $48 \mathrm{~h}$ of NF-kB inhibition. It is anticipated that TNBC cells would have a distinct response pattern compared with the other cells due to their different histological origin. Despite the lack of a known potent signaling pathway to deal properly with redox variations [50,51], NF-kB-silenced MDA-MB-231 exhibited important components of the antioxidant arm of the redox balance in the microarray analysis, such as glutathione peroxidase (GPX2), glutathione transferases (GSTM1, GSTK1, GSTP1, GSTT1 and GSTT2), ceruloplasmin (CP) and selenoprotein (SEPW1) (Table 2). Overexpression of ROS scavenger enzymes in TNBC has been associated with a good prognosis [57]. NF-KB inhibition for $48 \mathrm{~h}$ restored the thiol content and equilibrated the differences in the lipid peroxidation profile observed between the treated sample and its control, although the treated group retained elevated peroxidation. These findings suggest that after NF-KB inhibition, these cells may activate a late compensatory pathway that restores the antioxidant capacity. Thus, there may be some compensatory mechanism in cells that triggers increased thiol production likely to contain stress, which is in accordance with the findings of Kim et al. [57], who reported that increased expression of enzyme scavengers is associated with a better prognosis.

It is important to highlight that cancer cells are under continuous oxidative stress and, thus, present mechanisms to overcome and adapt to this situation. Since mild oxidative stress is a pivotal condition to ensure genomic instability, cells will utilize necessary compensatory mechanisms to ensure this condition. As we showed, different breast cancer cell types exhibit distinct patterns of redox-related genes. Furthermore, NF- $\mathrm{kB}$ may represent an additional mechanism related to oxidative stress maintenance in these cells, which operates in various forms to mediate other important predominant signaling components present in cancer cells.

Supplementary Materials: The following are available online at http:/ /www.mdpi.com/2073-4425/9/7/320/s1, Figure S1. Endogenous levels of lipid peroxidation (A), thiol content (B) and $\mathrm{NO}$ (C) in the untreated condition of MCF-7, HCC-1954 and MDA-MB-231 cells at 24 and 48 h. Figure S2. Relative mRNA expression of NF-B/p65 in MCF-7, HCC-1954 and MDA-MB-231 cells.

Author Contributions: B.R.B.P., C.P., R.B. and E.A. conceived and designed the experiments; B.R.B.P., R.B., G.M.F. and C.P. performed the experiments; B.R.B.P., R.B., G.M.F. and C.P. analyzed the data; R.C. and E.A. contributed reagents/materials/analysis tools; B.R.B.P. and C.P. wrote the paper.

Acknowledgments: This work was supported by grants from the Conselho Nacional de Desenvolvimento Científico e Tecnológico (CNPq), Ministério da Saúde (MS), Institutos Nacionais de Ciência e Teconologia (INCT)-Câncer and Fundação de Amparo à Pesquisa do Estado do Rio de Janeiro (FAPERJ). The authors are grateful to Kazuo Umezawa (Keio University, Japan) for providing an aliquot of DHMEQ. We also thank Rafael C. M. C. Silva, Vanessa J. Victorino, Juliana Cazarin de Menezes and Pedro Nicolau Neto for their relevant comments.

Conflicts of Interest: The authors declare no conflict of interest.

\section{References}

1. Siegel, R.L.; Miller, K.D.; Jemal, A. Cancer statistics, 2018. CA Cancer J. Clin. 2018, 68, 7-30. [CrossRef] [PubMed]

2. Polyak, K.; Metzger Filho, O. Snapshot: Breast cancer. Cancer Cell 2012, 22, 562. [CrossRef] [PubMed]

3. Voduc, K.D.; Cheang, M.C.; Tyldesley, S.; Gelmon, K.; Nielsen, T.O.; Kennecke, H. Breast cancer subtypes and the risk of local and regional relapse. J. Clin. Oncol. 2010, 28, 1684-1691. [CrossRef] [PubMed]

4. Pires, B.R.B.; Silva, R.; Ferreira, G.M.; Abdelhay, E. NF-kappaB: Two sides of the same coin. Genes 2018, 9, 24. [CrossRef] [PubMed]

5. Gupta, S.C.; Sundaram, C.; Reuter, S.; Aggarwal, B.B. Inhibiting NF- $\mathrm{\beta} \beta$ activation by small molecules as a therapeutic strategy. Biochim. Biophys. Acta 2010, 1799, 775-787. [CrossRef] [PubMed]

6. Vandenabeele, P.; Galluzzi, L.; Vanden Berghe, T.; Kroemer, G. Molecular mechanisms of necroptosis: An ordered cellular explosion. Nat. Rev. Mol. Cell Biol. 2010, 11, 700-714. [CrossRef] [PubMed]

7. Sun, S.C. Non-canonical NF- $\mathrm{\beta} \beta$ signaling pathway. Cell Res. 2011, 21, 71-85. [CrossRef] [PubMed] 
8. Colotta, F.; Allavena, P.; Sica, A.; Garlanda, C.; Mantovani, A. Cancer-related inflammation, the seventh hallmark of cancer: Links to genetic instability. Carcinogenesis 2009, 30, 1073-1081. [CrossRef] [PubMed]

9. Hanahan, D.; Weinberg, R.A. Hallmarks of cancer: The next generation. Cell 2011, 144, 646-674. [CrossRef] [PubMed]

10. Biswas, D.K.; Iglehart, J.D. Linkage between EGFR family receptors and nuclear factor kappaB (NF- $\kappa \beta)$ signaling in breast cancer. J. Cell. Physiol. 2006, 209, 645-652. [CrossRef] [PubMed]

11. Hinohara, K.; Kobayashi, S.; Kanauchi, H.; Shimizu, S.; Nishioka, K.; Tsuji, E.; Tada, K.; Umezawa, K.; Mori, M.; Ogawa, T.; et al. ErbB receptor tyrosine kinase/NF- $\beta \beta$ signaling controls mammosphere formation in human breast cancer. Proc. Natl. Acad. Sci. USA 2012, 109, 6584-6589. [CrossRef] [PubMed]

12. Huber, M.A.; Azoitei, N.; Baumann, B.; Grunert, S.; Sommer, A.; Pehamberger, H.; Kraut, N.; Beug, H.; Wirth, T. NF- $\kappa \beta$ is essential for epithelial-mesenchymal transition and metastasis in a model of breast cancer progression. J. Clin. Investig. 2004, 114, 569-581. [CrossRef] [PubMed]

13. Kendellen, M.F.; Bradford, J.W.; Lawrence, C.L.; Clark, K.S.; Baldwin, A.S. Canonical and non-canonical NF-K $\beta$ signaling promotes breast cancer tumor-initiating cells. Oncogene 2014, 33, 1297-1305. [CrossRef] [PubMed]

14. Liu, M.; Sakamaki, T.; Casimiro, M.C.; Willmarth, N.E.; Quong, A.A.; Ju, X.; Ojeifo, J.; Jiao, X.; Yeow, W.S.; Katiyar, S.; et al. The canonical NF- $\kappa \beta$ pathway governs mammary tumorigenesis in transgenic mice and tumor stem cell expansion. Cancer Res. 2010, 70, 10464-10473. [CrossRef] [PubMed]

15. Merkhofer, E.C.; Cogswell, P.; Baldwin, A.S. HER2 activates NF- $k \beta$ and induces invasion through the canonical pathway involving IKK $\alpha$. Oncogene 2010, 29, 1238-1248. [CrossRef] [PubMed]

16. Pratt, M.A.; Tibbo, E.; Robertson, S.J.; Jansson, D.; Hurst, K.; Perez-Iratxeta, C.; Lau, R.; Niu, M.Y. The canonical NF- $\kappa \beta$ pathway is required for formation of luminal mammary neoplasias and is activated in the mammary progenitor population. Oncogene 2009, 28, 2710-2722. [CrossRef] [PubMed]

17. Schramek, D.; Leibbrandt, A.; Sigl, V.; Kenner, L.; Pospisilik, J.A.; Lee, H.J.; Hanada, R.; Joshi, P.A.; Aliprantis, A.; Glimcher, L.; et al. Osteoclast differentiation factor RANKL controls development of progestin-driven mammary cancer. Nature 2010, 468, 98-102. [CrossRef] [PubMed]

18. Pires, B.R.; Mencalha, A.L.; Ferreira, G.M.; de Souza, W.F.; Morgado-Diaz, J.A.; Maia, A.M.; Correa, S.; Abdelhay, E.S. NF- $\kappa \beta$ is involved in the regulation of EMT genes in breast cancer cells. PLoS ONE 2017, 12, e0169622. [CrossRef] [PubMed]

19. Kanehisa Laboratories. Kyoto Encyclopedia of Genes and Genomes. Available online: http://genome.jp/ $\mathrm{kegg} /$ (accessed on 1 May 2018).

20. Mi, H.; Huang, X.; Muruganujan, A.; Tang, H.; Mills, C.; Kang, D.; Thomas, P.D. PANTHER version 11: expanded annotation data from Gene Ontology and Reactome pathways, and data analysis tool enhancements. Nucl. Acids Res. 2016. [CrossRef] [PubMed]

21. VIB/Ugent Bioinformatics \& Evolutionary Genomics Technologiepark. Available online: http:// bioinformatics.psb.ugent.be/software/details/Venn-Diagrams (accessed on 1 May 2018).

22. Livak, K.J.; Schmittgen, T.D. Analysis of relative gene expression data using real-time quantitative PCR and the $2^{-\triangle \Delta C T}$ method. Methods 2001, 25, 402-408. [CrossRef] [PubMed]

23. Sedlak, J.; Lindsay, R.H. Estimation of total, protein-bound, and nonprotein sulfhydryl groups in tissue with Ellman's reagent. Anal. Biochem. 1968, 25, 192-205. [CrossRef]

24. Panis, C.; Victorino, V.J.; Herrera, A.C.; Freitas, L.F.; De Rossi, T.; Campos, F.C.; Simao, A.N.; Barbosa, D.S.; Pinge-Filho, P.; Cecchini, R.; et al. Differential oxidative status and immune characterization of the early and advanced stages of human breast cancer. Breast Cancer Res. Treat. 2012, 133, 881-888. [CrossRef] [PubMed]

25. Gonzalez Flecha, B.; Llesuy, S.; Boveris, A. Hydroperoxide-initiated chemiluminescence: An assay for oxidative stress in biopsies of heart, liver, and muscle. Free Rad. Biol. Med. 1991, 10, 93-100. [CrossRef]

26. Bacolla, A.; Cooper, D.N.; Vasquez, K.M. Mechanisms of base substitution mutagenesis in cancer genomes. Genes 2014, 5, 108-146. [CrossRef] [PubMed]

27. Gao, Y.; Mutter-Rottmayer, E.; Zlatanou, A.; Vaziri, C.; Yang, Y. Mechanisms of post-replication DNA repair. Genes 2017, 8, 64. [CrossRef] [PubMed]

28. Iyer, D.R.; Rhind, N. The intra-S checkpoint responses to DNA damage. Genes 2017, 8, 74. [CrossRef] [PubMed]

29. Mertz, T.M.; Harcy, V.; Roberts, S.A. Risks at the DNA replication fork: Effects upon carcinogenesis and tumor heterogeneity. Genes 2017, 8, 46. [CrossRef] [PubMed] 
30. Marinello, P.C.; Machado, K.L.; Cecchini, R.; Cecchini, A.L. The participation of oxidative stress in breast cancer cells progression and treatment resistance. Am. J. Immunol. 2014, 10, 207-214. [CrossRef]

31. Panis, C.; Victorino, V.; Herrera, A.; Cecchini, A.; Simão, A.; Tomita, L.; Cecchini, R. Can breast tumors affect the oxidative status of the surrounding environment? A comparative analysis among cancerous breast, mammary adjacent tissue, and plasma. Oxid. Med. Cell. Longev. 2016, 2016, 6429812. [CrossRef] [PubMed]

32. Victorino, V.J.; Aranome, A.M.F.; de Campos, F.C.; do Amaral, A.C.D.S.; Cecchini, R.; Panis, C. Crosstalk between oxidative stress signaling and HER2 pathway in breast cancer. Am. J. Immunol. 2014, 10, 176. [CrossRef]

33. Arcucci, A.; Ruocco, M.R.; Granato, G.; Sacco, A.M.; Montagnani, S. Cancer: An oxidative crosstalk between solid tumor cells and cancer associated fibroblasts. BioMed Res. Int. 2016, 2016, 4502846. [CrossRef] [PubMed]

34. Karin, M. Nuclear factor- $\kappa \beta$ in cancer development and progression. Nature 2006, 441, 431-436. [CrossRef] [PubMed]

35. Bartling, B.; Hofmann, H.S.; Boettger, T.; Hansen, G.; Burdach, S.; Silber, R.E.; Simm, A. Comparative application of antibody and gene array for expression profiling in human squamous cell lung carcinoma. Lung Cancer 2005, 49, 145-154. [CrossRef] [PubMed]

36. Pang, E.Y.; Bai, A.H.; To, K.F.; Sy, S.M.; Wong, N.L.; Lai, P.B.; Squire, J.A.; Wong, N. Identification of PFTAIRE protein kinase 1, a novel cell division cycle-2 related gene, in the motile phenotype of hepatocellular carcinoma cells. Hepatology 2007, 46, 436-445. [CrossRef] [PubMed]

37. Lee, S.; Bang, S.; Song, K.; Lee, I. Differential expression in normal-adenoma-carcinoma sequence suggests complex molecular carcinogenesis in colon. Oncol. Rep. 2006, 16, 747-754. [CrossRef] [PubMed]

38. Pham, H.; Eibl, G.; Vincenti, R.; Chong, B.; Tai, H.H.; Slice, L.W. 15-Hydroxyprostaglandin dehydrogenase suppresses K-Ras ${ }^{\mathrm{V} 12}$-dependent tumor formation in $\mathrm{Nu} / \mathrm{Nu}$ mice. Mol. Carcinog. 2008, 47, 466-477. [CrossRef] [PubMed]

39. Thiel, A.; Ganesan, A.; Mrena, J.; Junnila, S.; Nykanen, A.; Hemmes, A.; Tai, H.H.; Monni, O.; Kokkola, A.; Haglund, C.; et al. 15-Hydroxyprostaglandin dehydrogenase is down-regulated in gastric cancer. Clin. Cancer Res. 2009, 15, 4572-4580. [CrossRef] [PubMed]

40. Uhlén, M.; Fagerberg, L.; Hallström, B.M.; Lindskog, C.; Oksvold, P.; Mardinoglu, A.; Sivertsson, Å.; Kampf, C.; Sjöstedt, E.; Asplund, A.; et al. Tissue-based map of the human proteome. Science 2015, $347,1260419$.

41. Fuchs, O. Transcription factor NF- $\kappa \beta$ inhibitors as single therapeutic agents or in combination with classical chemotherapeutic agents for the treatment of hematologic malignancies. Curr. Mol. Pharmacol. 2010, 3, 98-122. [CrossRef] [PubMed]

42. Gilmore, T.D.; Garbati, M.R. Inhibition of NF- $k \beta$ signaling as a strategy in disease therapy. Curr. Top. Microbiol. Immunol. 2011, 349, 245-263. [PubMed]

43. Watanabe, M.; Nakashima, M.; Togano, T.; Higashihara, M.; Watanabe, T.; Umezawa, K.; Horie, R. Identification of the RelA domain responsible for action of a new NF- $\kappa \beta$ inhibitor DHMEQ. Biochem. Biophys. Res. Commun. 2008, 376, 310-314. [CrossRef] [PubMed]

44. Matsumoto, G.; Namekawa, J.; Muta, M.; Nakamura, T.; Bando, H.; Tohyama, K.; Toi, M.; Umezawa, K. Targeting of nuclear factor $\kappa \beta$ pathways by dehydroxymethylepoxyquinomicin, a novel inhibitor of breast carcinomas: Antitumor and antiangiogenic potential in vivo. Clin. Cancer Res. 2005, 11, 1287-1293. [PubMed]

45. Victorino, V.J.; Campos, F.C.; Herrera, A.C.; Colado Simao, A.N.; Cecchini, A.L.; Panis, C.; Cecchini, R. Overexpression of HER-2/neu protein attenuates the oxidative systemic profile in women diagnosed with breast cancer. Tumour Biol. 2014, 35, 3025-3034. [CrossRef] [PubMed]

46. Jordan, N.V.; Bardia, A.; Wittner, B.S.; Benes, C.; Ligorio, M.; Zheng, Y.; Yu, M.; Sundaresan, T.K.; Licausi, J.A.; Desai, R.; et al. HER2 expression identifies dynamic functional states within circulating breast cancer cells. Nature 2016, 537, 102-106. [CrossRef] [PubMed]

47. Gago-Dominguez, M.; Castelao, J.E.; Pike, M.C.; Sevanian, A.; Haile, R.W. Role of lipid peroxidation in the epidemiology and prevention of breast cancer. Cancer Epidemiol. Biomark. Prev. 2005, 14, 2829-2839. [CrossRef] [PubMed]

48. Gago-Dominguez, M.; Jiang, X.; Castelao, J.E. Lipid peroxidation, oxidative stress genes and dietary factors in breast cancer protection: A hypothesis. Breast Cancer Res. 2007, 9, 201. [CrossRef] [PubMed]

49. Mencalha, A.; Victorino, V.J.; Cecchini, R.; Panis, C. Mapping oxidative changes in breast cancer: Understanding the basic to reach the clinics. Anticancer Res. 2014, 34, 1127-1140. [PubMed] 
50. Jakovcevic, D.; Dedic-Plavetic, N.; Vrbanec, D.; Jakovcevic, A.; Jakic-Razumovic, J. Breast cancer molecular subtypes and oxidative DNA damage. Appl. Immunohistochem. Mol. Morphol. 2015, 23, 696-703. [CrossRef] [PubMed]

51. Karihtala, P.; Kauppila, S.; Soini, Y.; Arja Jukkola, V. Oxidative stress and counteracting mechanisms in hormone receptor positive, triple-negative and basal-like breast carcinomas. BMC Cancer 2011, 11, 262. [CrossRef] [PubMed]

52. Mann, V.; Huber, C.; Kogianni, G.; Collins, F.; Noble, B. The antioxidant effect of estrogen and selective estrogen receptor modulators in the inhibition of osteocyte apoptosis in vitro. Bone 2007, 40, 674-684. [CrossRef] [PubMed]

53. Marathe, N.; Rangaswami, H.; Zhuang, S.; Boss, G.R.; Pilz, R.B. Pro-survival effects of $17 \beta$-estradiol on osteocytes are mediated by nitric oxide/cGMP via differential actions of cGMP-dependent protein kinases I and II. J. Biol. Chem. 2012, 287, 978-988. [CrossRef] [PubMed]

54. Gionet, N.; Jansson, D.; Mader, S.; Pratt, M.A. NF- $\kappa \beta$ and estrogen receptor $\alpha$ interactions: Differential function in estrogen receptor-negative and -positive hormone-independent breast cancer cells. J. Cell. Biochem. 2009, 107, 448-459. [CrossRef] [PubMed]

55. Matthews, J.R.; Botting, C.H.; Panico, M.; Morris, H.R.; Hay, R.T. Inhibition of NF-k $\beta$ DNA binding by nitric oxide. Nucleic Acids Res. 1996, 24, 2236-2242. [CrossRef] [PubMed]

56. Hoesel, B.; Schmid, J.A. The complexity of NF- $\kappa \beta$ signaling in inflammation and cancer. Mol. Cancer 2013, 12, 86. [CrossRef] [PubMed]

57. Kim, D.; Koo, J.S.; Lee, S. Overexpression of reactive oxygen species scavenger enzymes is associated with a good prognosis in triple-negative breast cancer. Oncology 2015, 88, 9-17. [CrossRef] [PubMed]

(C) 2018 by the authors. Licensee MDPI, Basel, Switzerland. This article is an open access article distributed under the terms and conditions of the Creative Commons Attribution (CC BY) license (http:/ / creativecommons.org/licenses/by/4.0/). 